Journal of Social Sciences (COES\&RJ-JSS)

ISSN (E): 2305-9249 ISSN (P): 2305-9494

Publisher: Centre of Excellence for Scientific \& Research Journalism, COES\&RJ LLC

Online Publication Date: $1^{\text {st }}$ January 2019

Online Issue: Volume 8, Number 1, January 2019

https://doi.org/10.25255/jss.2019.8.1.63.89

\title{
Real estate documentation and its importance in Islamic jurisprudence and law
}

\author{
Habis Motreb Hdisan Shammari \\ Education Department, Qurayyat Governorate, Saudi Arabia \\ Al-Qurayyat, Saudi Arabia \\ E-mail: habisalshamari@gmail.com
}

\begin{abstract}
:
There is no doubt that dealing with people from the sale, purchase, lease and other contracts is necessary and inevitable, and the society does not dispense with them in any way. The wisdom of God necessitated the enactment of these transactions and contracts governing the relations. In the various types of transactions and exchanges, and to ensure that everyone has the right, and documentation is one of the important and necessary means to ensure that; in order to resolve the dispute and conflict that may prevail these relations; God revealed any Koran is the religion which is the longest The Koran where the foundations laid.

The documentation is a science in which the Arabs excelled, and increased interest after the emergence of Islam and the spread of writing in the Arabian Peninsula, and the attention of jurists of old and recent and put a lot of rules and foundations and the provisions relating to the provisions of the notary and the writing of the document so that rights holders to know their rights and obligations May be taken by some as a means of repudiation of the obligation of the contract or agreement; because of the nature of human frailty and love of self and injustice and longing to the debris of the world fleeting, as well as certification and mortgage and other means of documentation The researcher has followed the method of inductive and analytical, through the extrapolation of legal texts and their analysis and knowledge of the provisions related to them, and the study has concluded that the documentation of all kinds of means used to strengthen rights in conflict, and has a significant role in the preservation of rights and .maintenance of the arrogance
\end{abstract}

Keywords:

Documentation, Certificate, Ownership

\section{Citation:}

Shammari, Habis Motreb Hdisan; (2019); Real estate documentation and its importance in Islamic jurisprudence and law; Journal of Social Sciences (COES\&RJ-JSS), Vol.8, No.1, pp:63-89; https://doi.org/10.25255/jss.2019.8.1.63.89.

This work is licensed under a Creative Commons Attribution 4.0 International License. 
عنوان البحث : التوثيق العقاري وأهميته في الفقه الاسلامي والقانون .

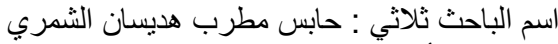

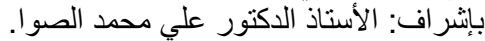

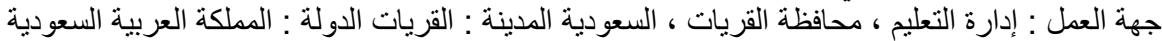
habisalshamari@gmail.com : البريد الالكتروني :

الملخص

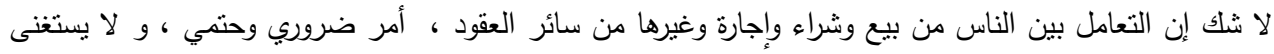

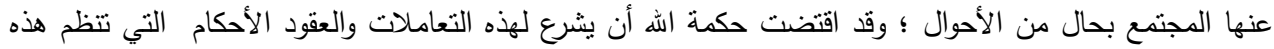

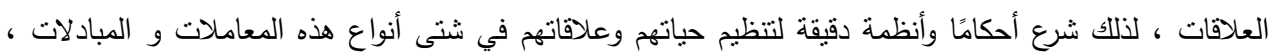

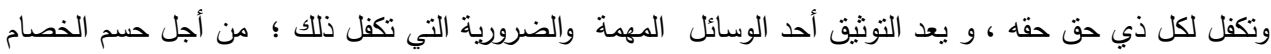

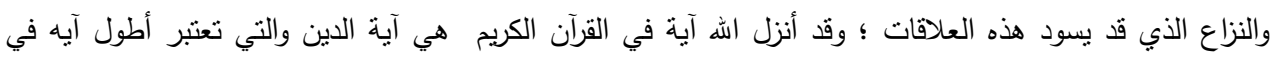

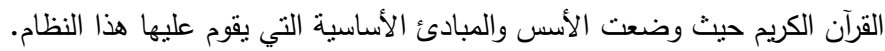
ويعد التوثيق من العلوم التي برع فيها العرب ، وازداد الإهتمام به بعد ظهور الإسلام وإنتشار الكتابة في الجزيرة

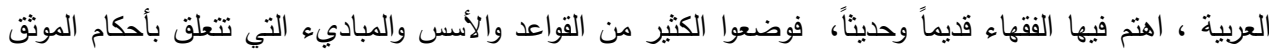

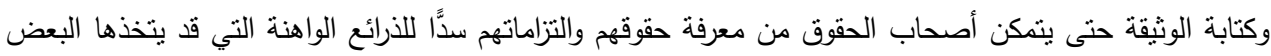

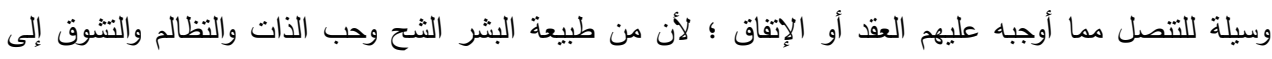

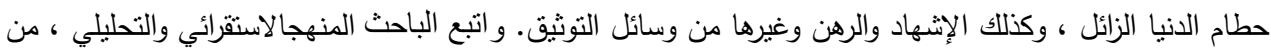

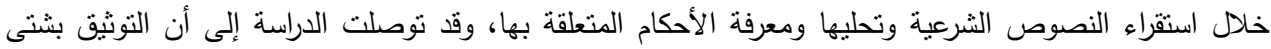
أنواعه من الوسائل التي تستخدم لتقوية الحقوق عند النتازع ، وله دور كبير في حفظ الحقوق وصيانتها من الجحود.

الكلمات الافتاحيية

النوثيق ، الثهادة ، الملكية

المقدمة

الحمد لله الذي خلق الإنسان وعلمه وسخر له الأرض يستعمره فيها ، وأنشهد أن لا إله إلا الهه وأثشهد أن محمداً عبده

$$
\text { ورسوله وبعد }
$$

لقد عنيت الشريعة الإسلامية بالعقود عناية كبيرةوبالغة ، وهذا ما نلحظه من اهنمامها بكل عقد على إنفراده ، وكذلك الكات

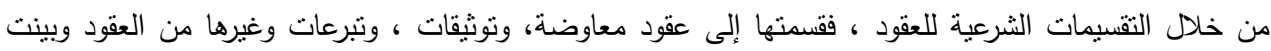

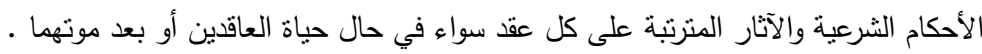

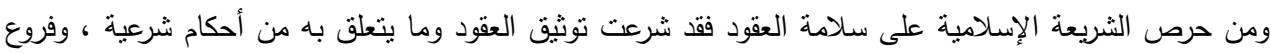

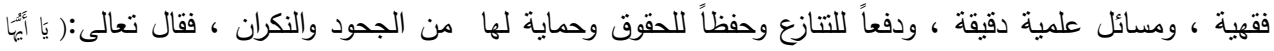

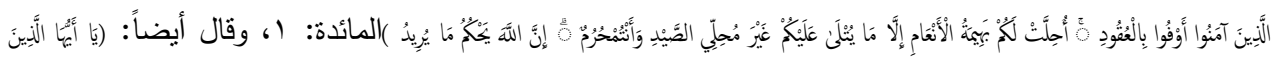

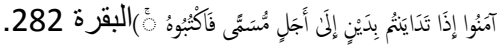
ولأهمية هذا الموضوع فقد ارتأيت أن أكتب في التوثيق العقاري وبيان أهميته ، وحاجة الناس إليه، و التوثيق العقاري

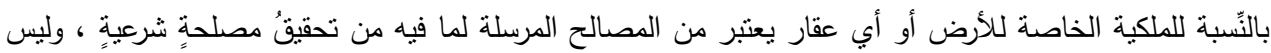

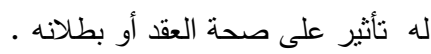
فقد مضت سنة النبي عليه السلام في عقود الزواج والطلاق والبيع والثشراء من غير توثيق وبعضها بتوثيق . 


\section{Real estate documentation and its importance in Islamic jurisprudence and law}

وفي هذا العصر فقد أصبح التوثيق من مقتضيات الدولة ، وتم إنثاء الكثير من الدوائر والمكاتب التي تعنى بهذا الأمر وذلك لحاجة الناس إليه ، وفساد الذمم عند الكثير من الناس ، وكثثة التعمالات فقد استدعى الأمر إلى الإهتمام

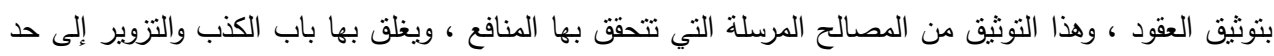
كبير.

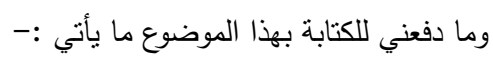
1. إن البحث في توثيق العقود وخصوصاً العقود المتعلقة بالملكية الخاصةتلأرض والعقار ولما لها أهية كبيره في حفظ

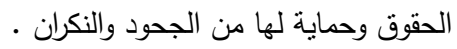
2. حاجة المسلمين لمعرفة الأحكام المتعلقة بتوثيق الملكية الخاصة للأرض ومان ولئ هي الآثار المترتبة على التوثيق.

أمر الله المؤمنين بكتابة الديون والعقود وسائر المعاملات وتوثيقها في أطول آية في القرآن الكريم ، مما يدل على العي

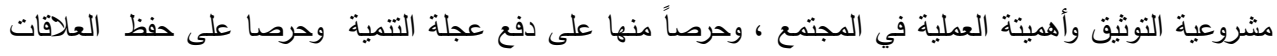
بين أفراد المجتمع وذللك بالبعد عن الخلاف والثقاق بين الناس ، من هنا استوجب علئ على أفراد المجتمع معرفة الأحكام

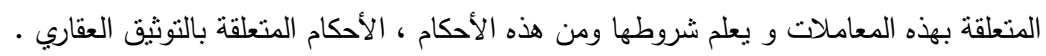
وتتبع أهمية هذا البحث في أنه يعالج بعض الأخطاء التي يقع فيها الكثير من الناس في حال البيع والثراء دون تونئ التئيق

مشكلة البحث.

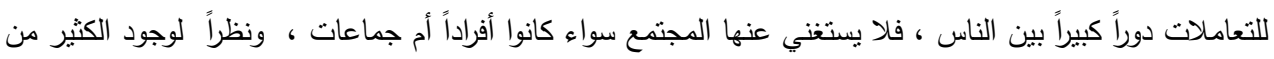

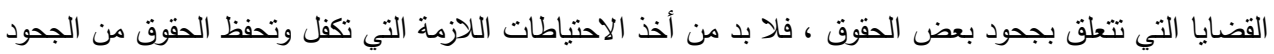

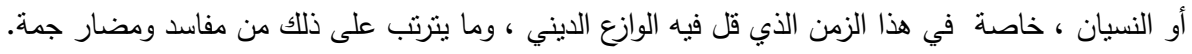

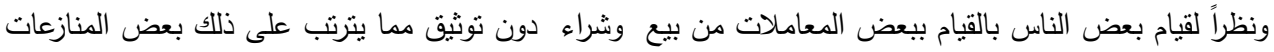

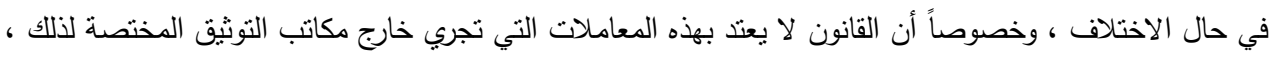

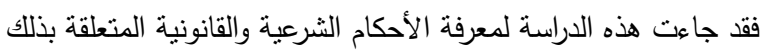
أسئلة البحث جات هن هناك أسئلة تدور حول موضوع الدراسة تتلخص فيما بأتي :-

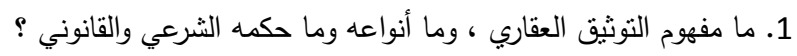

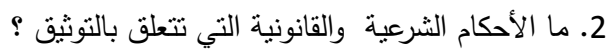

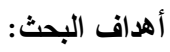
تكمن أهداف البحث في الآتي: 1.بيان ما مفهوم التوثيق العقاري، وما أنواعه وما حكمه الثرعي. 2.بيان الأحكام الشرعية الني نتعلق بالتوثيق.

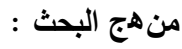

وأما المنهج الذي سأتبعه في هذه الدراسة هو المنهج الاستقرائي والنحليلي وذلك من خلال استقراء النصوص الثنرعية

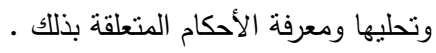
هيكلة البحث سيكون البحث حسب الخطة الأتية :- هبs 


$$
\begin{aligned}
& \text { المبحث الأول : التوثيق العقاري ، تعريفه ، نشأتة، وأنواعه . }
\end{aligned}
$$

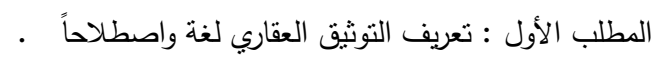

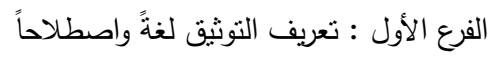

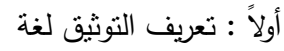

$$
\begin{aligned}
& \text { ثانياً : تعريف التوثيق اصطلاحاً } \\
& \text { الفرع الثاني : نعريف العقار لغة واصطلاحيا } \\
& \text { أولاً : تعريف العقار لغة : نعرئ }
\end{aligned}
$$

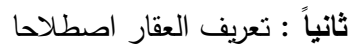

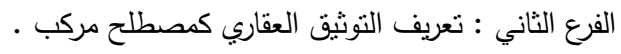

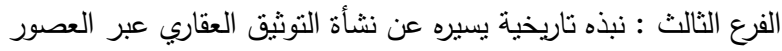

$$
\begin{aligned}
& \text { المطلب الثالث : أنواع التوثيق العقاري في الإنلام } \\
& \text { الفرع الأول : التوثيق بالكتابة }
\end{aligned}
$$

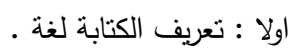

$$
\begin{aligned}
& \text { ثانيا: تعريف الكتابة اصطلاحا. } \\
& \text { ثالثاً: مشروعية الكتابة من القرآن والسنة النبوية . }
\end{aligned}
$$

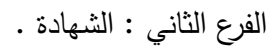

$$
\begin{aligned}
& \text { أولاً : تعريف الثهادة لغة واصطلاحا ـ الفهادة . }
\end{aligned}
$$

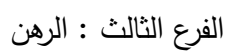

$$
\begin{aligned}
& \text { أولاً : تعريف الرهن لغة واصطلاحاً . } \\
& \text { 1.الرهن لغة . } \\
& \text { 2.الرهن في اصطلاح الفقهاء . } \\
& \text { الفرع الرابع : مشروعية التوثيق. }
\end{aligned}
$$

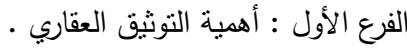

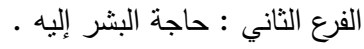

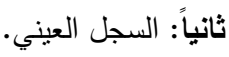

المبحث الأول : التوثيق العقاري ، تعريفه ، نثأته ،وأنواعه . 


\section{Real estate documentation and its importance in Islamic jurisprudence and law}

يعتبر التوثيق العقاري وسيلة مهمة في الفقه والقانون فهو وسيلة من وسائل حفظ الحقوق ، وقد حثت النصوص

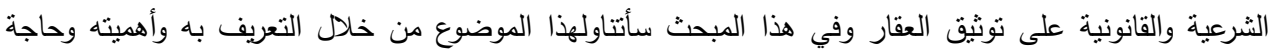

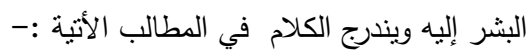
المطلب الأول : تعريف التوثيق العقاري لغةً واصطلاحهاً .

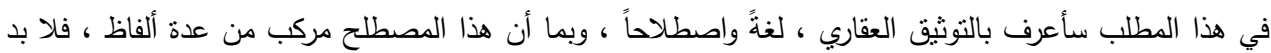

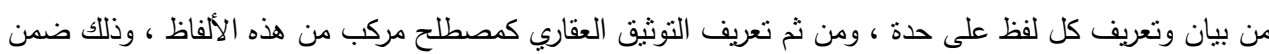

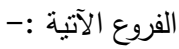

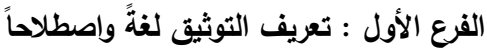
أولاً : تعريف التوثيق لغة : هناك الك عدة معان للتوثيق ومن هذه المعاني:

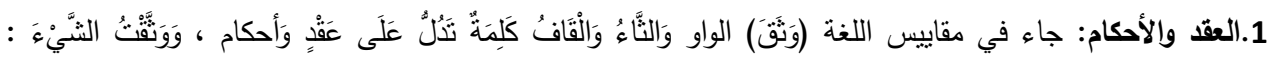

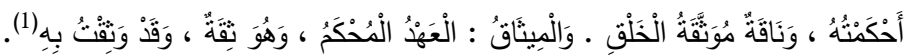

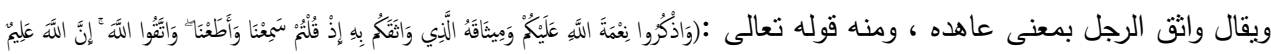

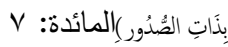

2.العهدوالإيمان، و كلمة نوثيق فهي مصدر للفعل وثق نقول : وثق الثيء نوثثقاً فهو موثق أب : محكم ، والوثيق

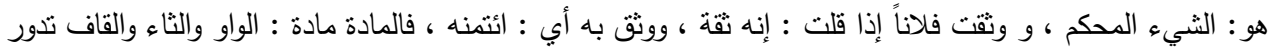

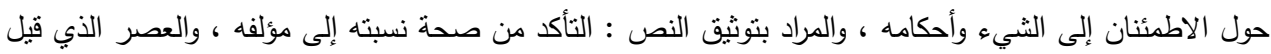

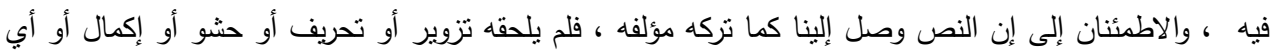

شيء من هذا القبيل ، وهو بذلك يصبح وثيقة من الوثائق يعني لا يتطرق إليه شك الثك (2).

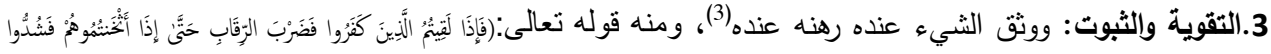

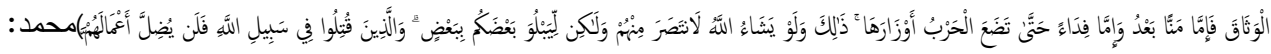

وجه الدلالة من الآية فثند الوثاق في الآية تدل على أن الهدف من الوثاق ليطمئن المسلمين من عدم هروب هؤلاء الأسرى من الأسر (4 ).

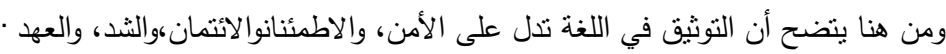
ثانياً : تعريف التوثيق اصطلاحاً

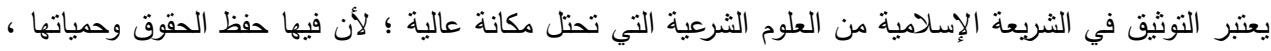

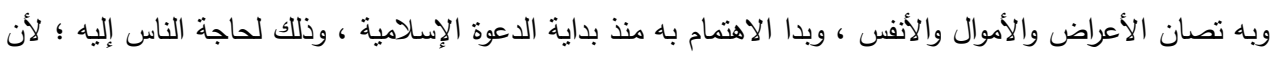

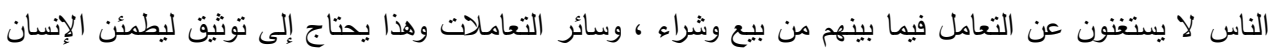

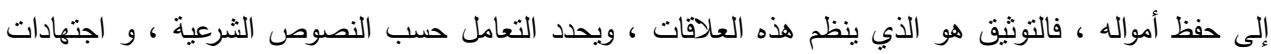

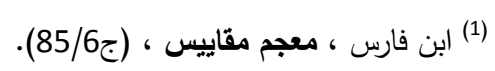

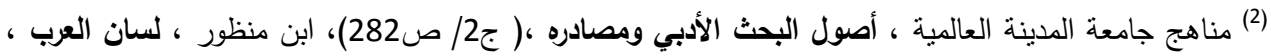

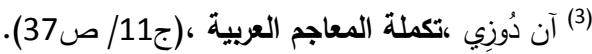

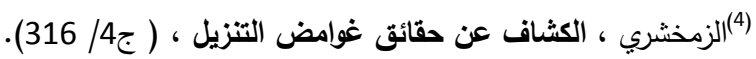




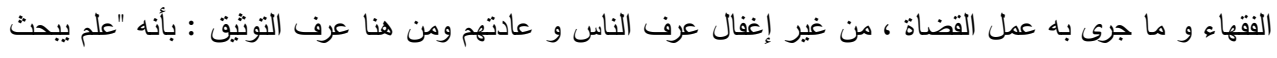
عن كيفية إثبات الأحكام الثابتةعند القاضي في الكتب والسجلات على وجه يصح الاحتجاجبه عند انقضاء شهود (5) الحال فموضوع النوثيق هو تلك الأحكام من حيث الكتابة ، ويستمد مبادئه من الفقه الإسلامي ، والبعض الأخر من علم

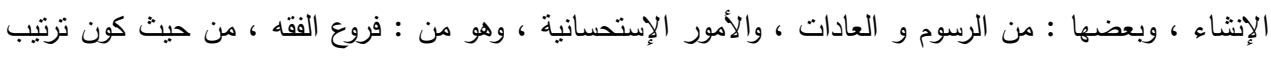

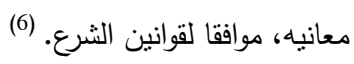

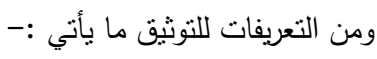
جاء في أبجد العلوم بأنه : " علم يبحث فيه عن إنثاء الكلمات المنعلقة بالأحكام ألثرعية ، وموضوعها ومنفعته ظاهرة

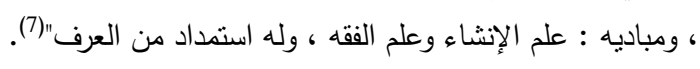
وعرف أيضاً بأنه : "عبارة عن مجموعة من الوسائل التي نؤدي إلى استيفاء الحق عند تعذره من المدين ، أو إثباته في ذمته عند الإنكار" (8). وعرف أيضا بأنه " خطة ينولاها العدول" المنصبون لكتابة العقود ، وضبط الثروط بين المتعاقدين في الأنكحة ،

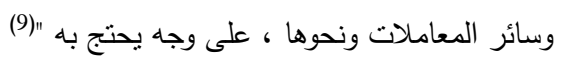

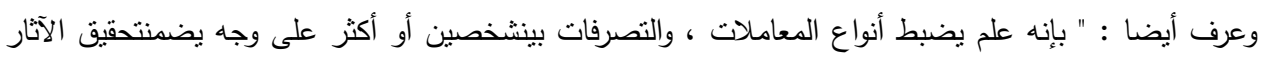

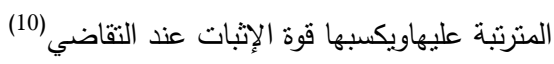
ولعل التعريف الاخير هو أفضل التعاريف لما يأني (11):1.تحديد شكل المعاملة والتصرف فيها حال وقوعها وما فيها من حفظ الوقائع المثبنة له من الزيادة والنقصان .

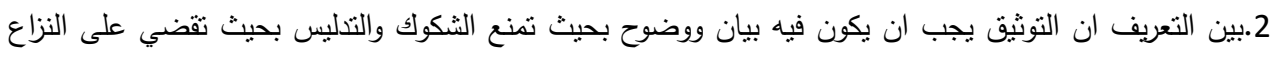

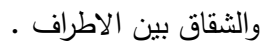
3. بين الغرض من الوثيقة وهو اثبات مضمونها عند القاضي

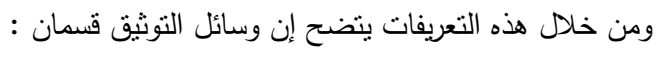

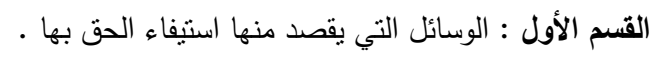

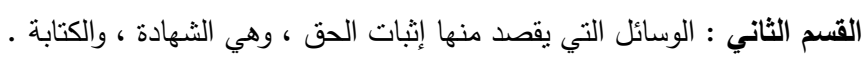

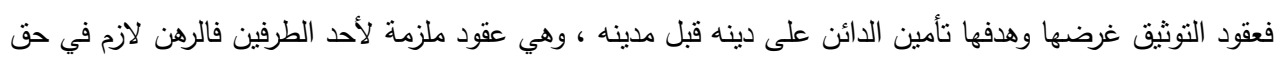
الراهن ، والضمان لازم في حق الضامن ، والكفالة لازمة في حق الكفيل وهكذا (12).

$$
\text { (5) ينظر : الحاج خليفة ، كثف الظنون عن أسامي الكتب والفنون ، (ج2/ ص1046). }
$$

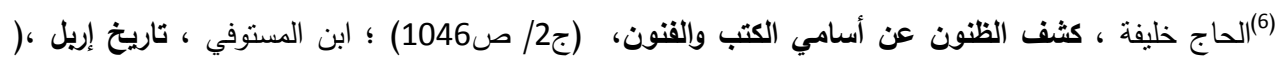

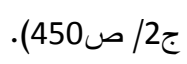

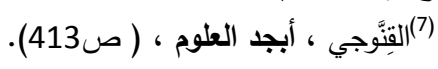

$$
\begin{aligned}
& \text { (8) الجريدان ،عقود التوثيق ،( بلا صفحه). }
\end{aligned}
$$

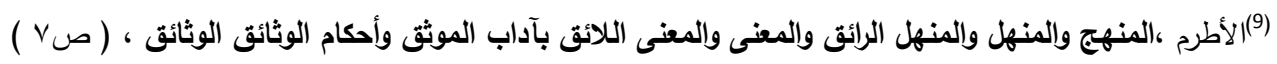

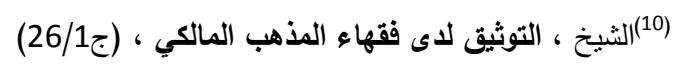

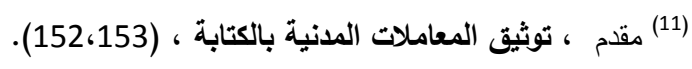
(12) الجريدان ، عقود التوثيق ، (بلا صفحه). 


\section{Real estate documentation and its importance in Islamic jurisprudence and law}

و ما جرى به عمل القضاة من غير إغفال عرف الناس و عاداتهم ، فهو إذن علم يبين عناصر كل اتفاقية معقودة

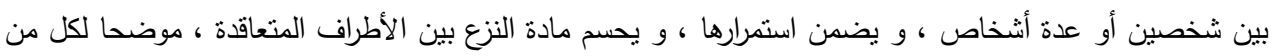

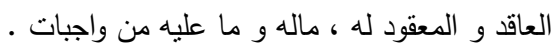

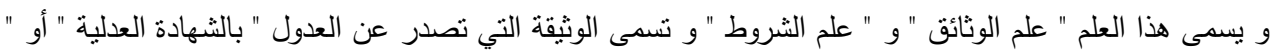
البينة " و هي أهم و سبلة لإثبات الحقوق و المعاملات و لذلك اعتتى بها الاسلام و نظم قواعدها و بين أحكامها قال

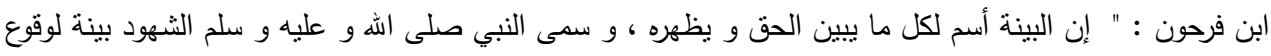
البيان بقولهم ، و ارتفاع الإشكال بشهادتهم "(13). الفرع الثاني : تعريف العقار لغة واصطلاحا

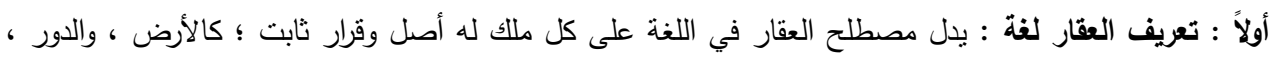

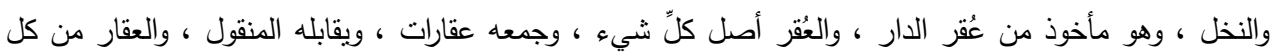

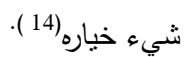
ثانياً : تعريف العقار اصطلاحا :- لقد عرف الفقهاء العقار بتعريفات مختلفة ومن هذه التعريفات ما بأتي :-

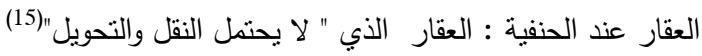

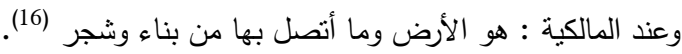

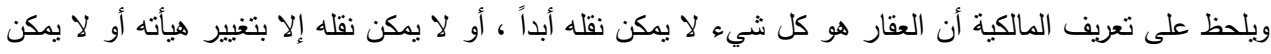

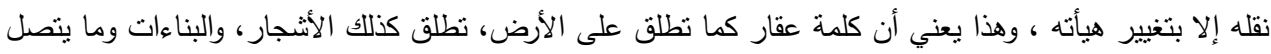

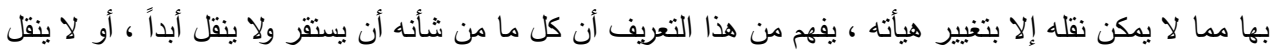

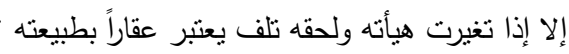

وأ ما الثافعية فعرفوا العقار : هو الأرض ، والبناء ، والغرس (17).

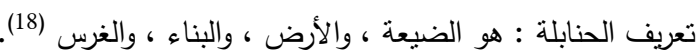

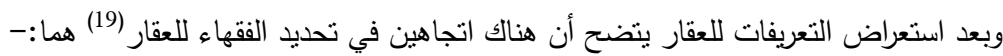

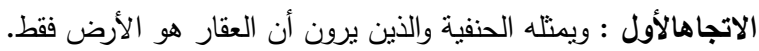
فالعقار عند الحنفية هو الثابت الذي لا يمكن نقله من مكان إلى آخر ؛ كالدور ، والأرضي (20).

(13) ينظر : ابن فرحون ، تبصرة الحكام ، (ج1/ 240).

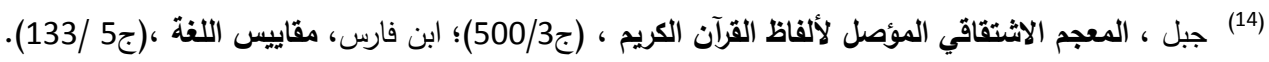

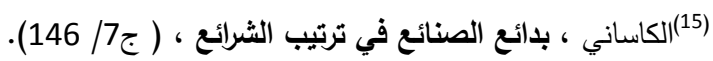

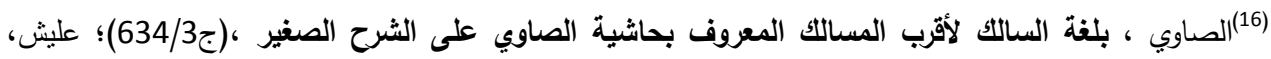

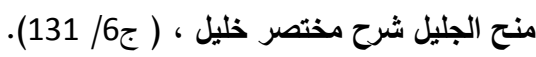

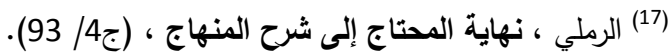

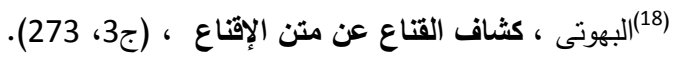

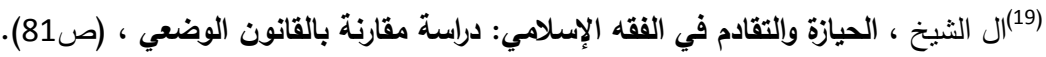

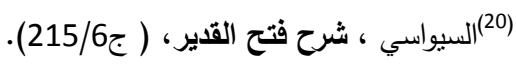




\section{Journal of Social Sciences (COES\&RJ-JSS), 8(1), pp.63-89}

فهم يطلقون على الغراس والبناء مسمى العقار بالتبع ، فالحجر من الدار إذا انهدمت يصبح مالاً منقولاً ، والثجر إذا اقتلع من أصله اعتبر هو الأخر من قبيل المنقول.

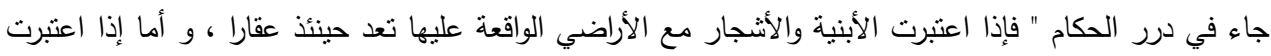
لوحدها بدون الأراضي الواقعة عليها فتعد منقولا (21).

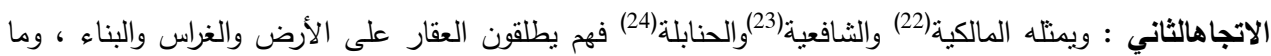
اتصل بها . فهم متفقون على أن ما لا يمكن نقله ، وتحويله من مكان إلى آخر يسمى عقارا ، وأن ما يمكن نقله وتحويله من مكان

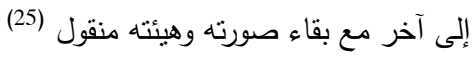

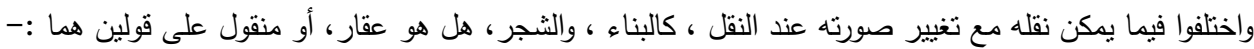

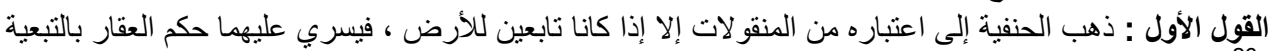

القول الثاني : ذهب الجمهور إلى اعتبار ذلك من العقار (27). ثمرة الخلاف في التعريفات عند الفقهاء تظهر ثمرة الخلاف في أن أصحاب الاتجاه الأول لا يقولون بالثفعة في الأشجار والأبنية إذا بيعت منفصلة عن الأرض ، بينما يجريها أصحاب الاتجاه الثاني باعتبار أنها من العقار (28).

جاء في الاقناع عند الحنابلة " ولا شفعة ولا فيما لبس بعقار كثجر وحيوان وبناء مفرد وجوهر وسيف ونحوها، إلا أن الغراس والبناء يؤخذان تبعا للأرض(29).

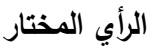

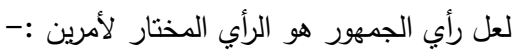
الأمر الأول : أنه موافق لما جاء في السنة النبوية من توسيع معنى العقار ليشمل النخل والغراس عموماً الأمر الثاني : اتفاقه مع التعريف اللغوي الذي يوسع معنى العقار، فالعقار هو الضيعة أو الدئه الدار أو الأرض :

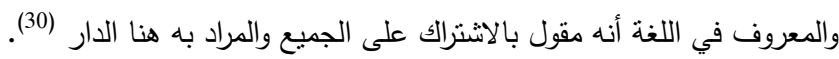

$$
\text { (21) أفندي ، درر الحكام في شرح مجلة الأحكام ، (ج1/ ص116). }
$$

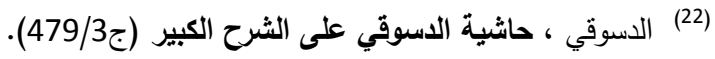

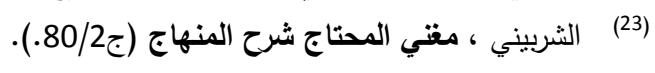

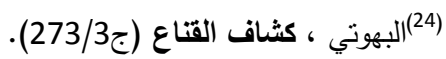

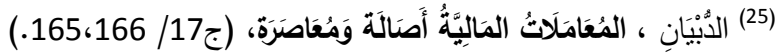

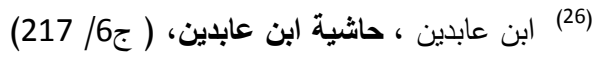

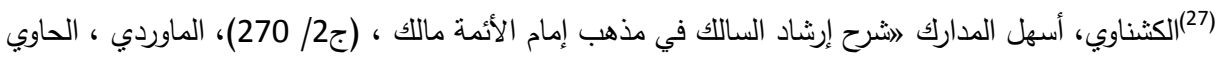

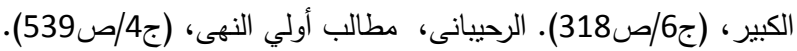

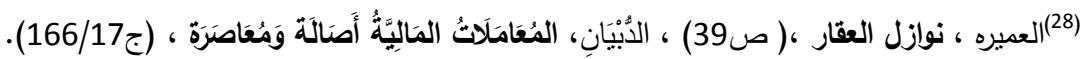

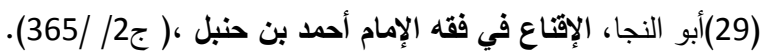

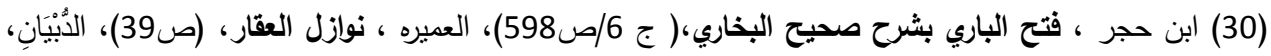

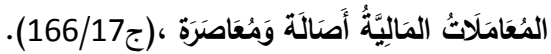




\section{Real estate documentation and its importance in Islamic jurisprudence and law}

ومن هنا نخلص إلى نتيجة إن التعريف اللغوي والاصطلاحي للعقار هو ما كان ثابتاً كالأرض والزرع والبناء .

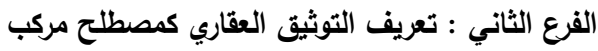
عرف التوثيق العقاري :بأنه الأحكام والإجراءات التي نكفل أحكام وإثبات العقار على وجها يصح الاحتجاج والتمسك به عند النتازع (31). وفي السعودية يطلق التوثيق العقاري على السجل العقاري ، فقد عرفت المادة الأولى من نظام التسجيل العيني للعقار في السعودية السجل العقاري بالآتي : السجل العقاري : مجموعة الوثائق التي تبين أوصاف كل عقار وموقعه وحالته الثرعية، وما له من حقوق وما عليه

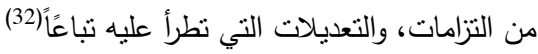
وأعطى النظام للسجل العقاري قوة إثباتية مطلقة فقد نصت المادة الثالثة من نظام النسجيل العيني للعقار في السعودية على : يكون للسجل العقاري قوة إثبات مطلقة ، ولا يجوز الطعن في بياناته بعد انتهاء الآجال المحددة للطعن

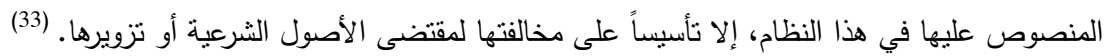

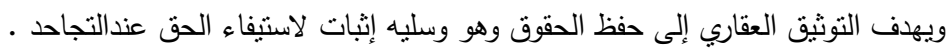

الفرع الثالث : نبذه تاريخية يسيره عن نثأة التوثيق العقاري عبر العصور

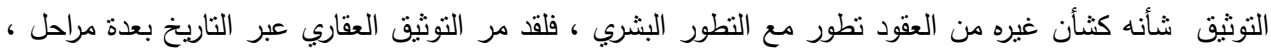

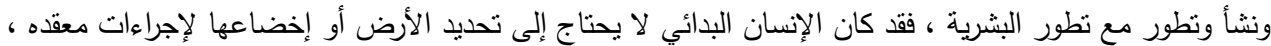
وحتى إنه لم يكن يعي معنى الملكية وصفاتها (34).

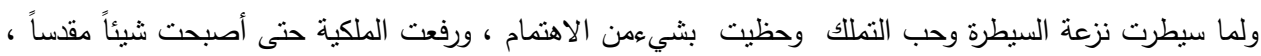

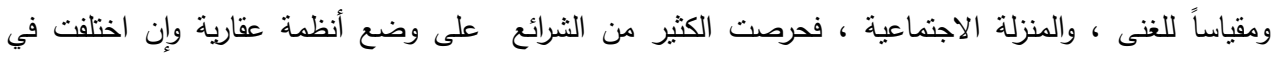

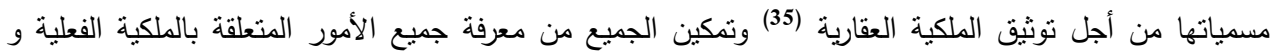

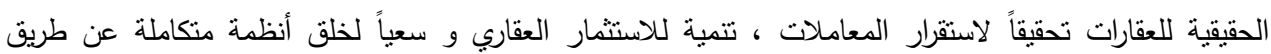

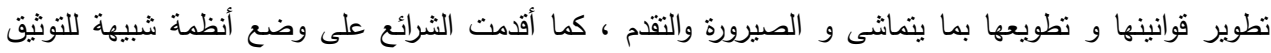
(36) (3قاريز

$$
\begin{aligned}
& \text { (31) يوسف القداجتظيم العقار وتوثيقه ( ص7). }
\end{aligned}
$$

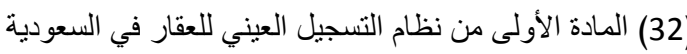

$$
\begin{aligned}
& \text { (33) المادة الثالثة من نظام التسجيل العيني للعقار في السعودية }
\end{aligned}
$$

(34) لقد اهتمت البشرية قديما بتوثيق الحقوق و التصرفات و المعاملات بطرق متعددة ، من اجل حفظ السجلات بواردات المعابد و الدولة ، فعمدوا الى صنع قوالب أحدثوا بها خدوشا ، راجع في ذلك ، روجرز ، قصة الكتابة و و

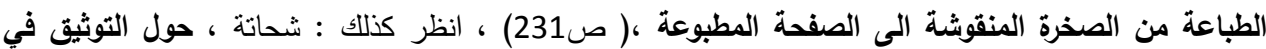
حضارات العرلق القديم ، (ص:143) . (35) تعتبر الأرض عصب الأنظمة الاقتصادية و الاجتماعية ، ويقى الإنسان دوما يسعى لنتظيمها و ضبطها حرصا

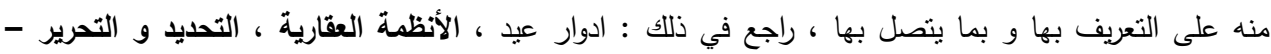

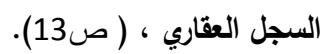
(36) ادوار عيد ، الأنظمة العقارية، (صنارئ) (13). 


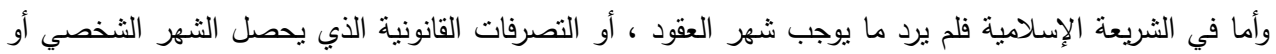

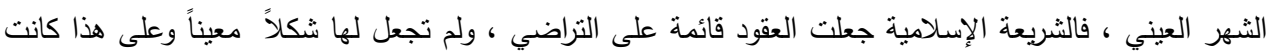

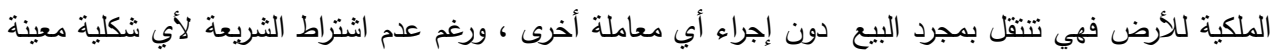

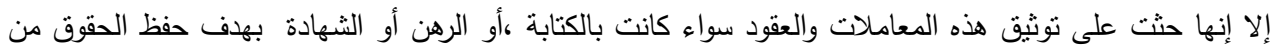

التجاحد) (37)

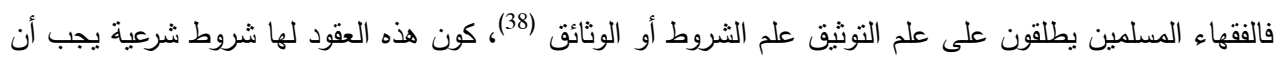
تتوفر فيها(39)كنلك القواعد الإدارية لتحقيق العلانية للتصرفات الواردة على العقارات عند الإغريق ، و بعض التص الألواح

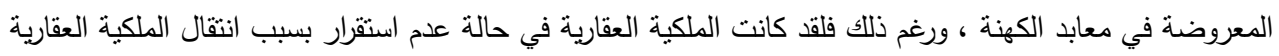
بمجرد النراضي والاتفاق، فالثخص كان يييع الأرض لأكثر من شخص رغم إنه ليس الئ مالكا لها في العديد من الأحيان

وفي الوقت الحاضر فقد دخل التوثيق في حياة الأفراد أنفسه فقلما تجد اليوم فرداً لا يقوم بنسجيل كل تصرف يحتاج

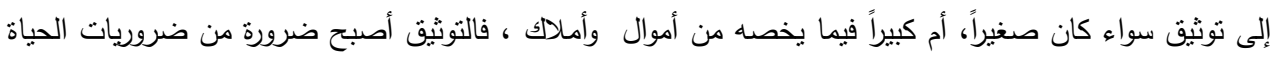

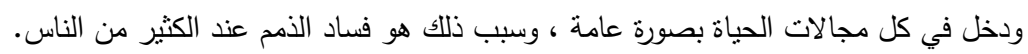

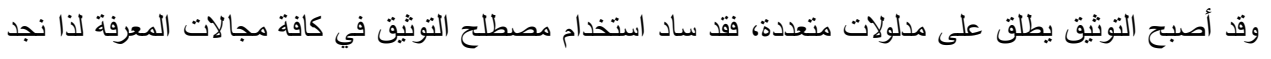

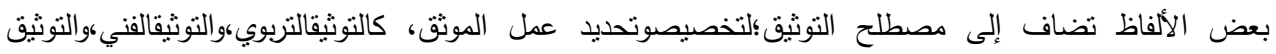
الإداري ونحو ذلك، أما التوثيق المقصود في مجال دراستتا فهوالتوثيق العقاري.

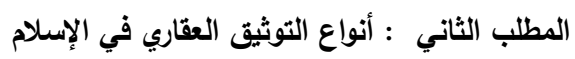

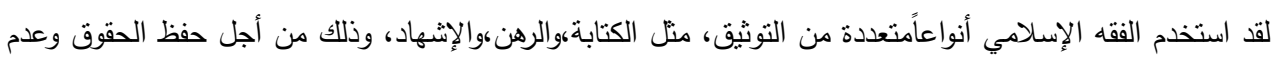

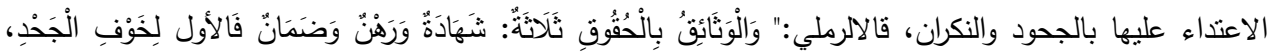

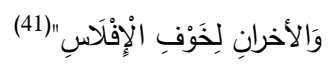

الفرع الأول : التوثيق بالكتابة

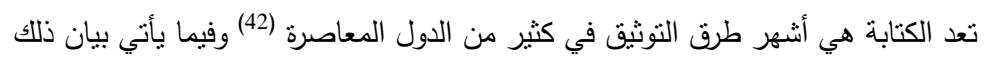

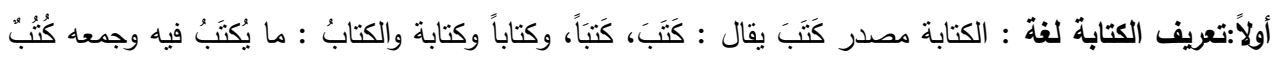

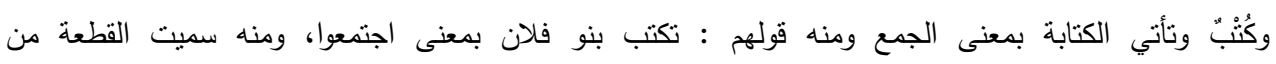

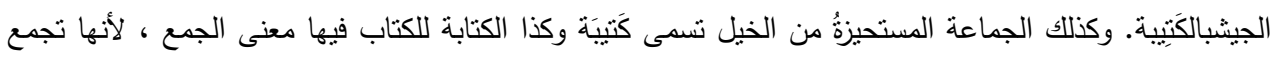

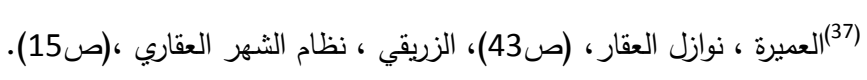

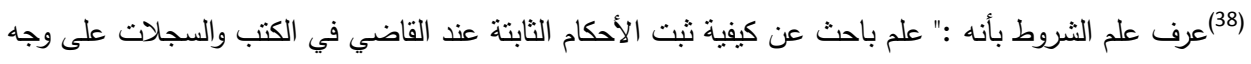

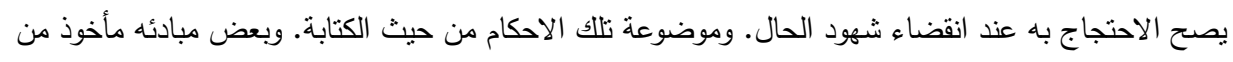

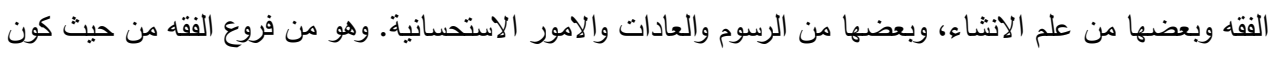

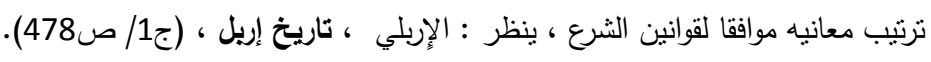

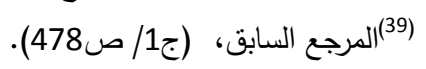

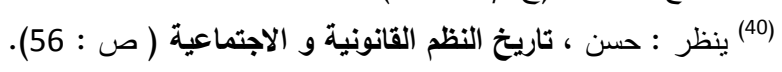

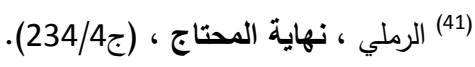

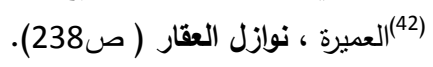




\section{Real estate documentation and its importance in Islamic jurisprudence and law}

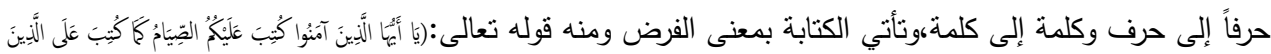

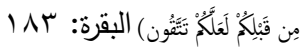

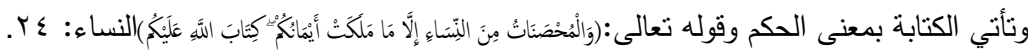
فالكتابة لغة بمعنى الخط ، وكتبه أب خطه ، وهوتصوير اللفظ بحروف هجائه وخط بالقلم أي كثب، واستكتب الثيء:

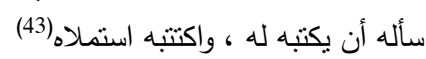
ثانياً : تعريف الكتابة اصطلاحاً :"هي الخط الذي يعتمدعليه في نوثيق الحقوق وما يتعلق بها، للرجوع إليه عند

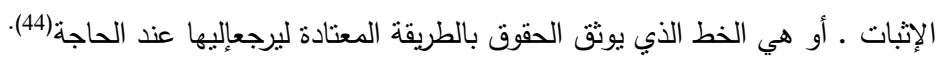

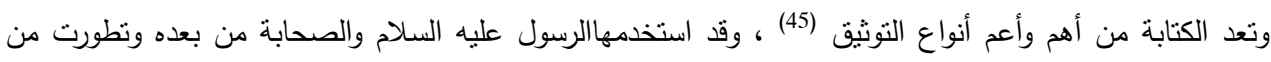

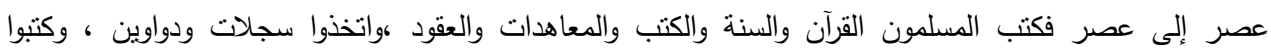

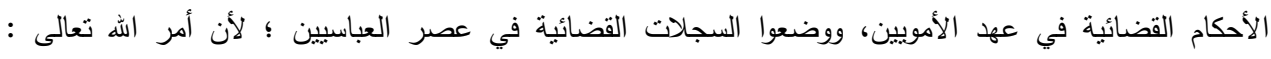

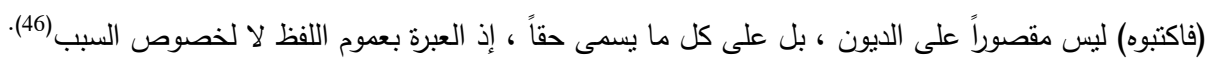

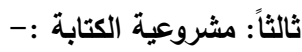
والكتابة للدين مشروعة في القرآن والسنة النبوية 1.من القرآن وكتابة المعاملات التي تجري بين الناس ، وسيلة قوية لتوثيقها وقد أمر اله سبحانه وتعالى بها في أطولآية في القرآن

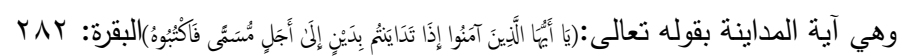

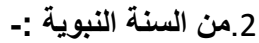
ومن السنة النبوية هناك الوقائع الكثيرة التي وثق فيها النبي صلى الله عليه وسلم بالكتابة في كثير من المعاملات ومن

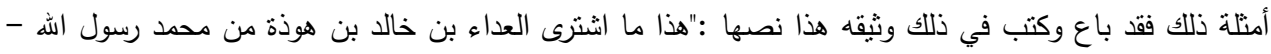

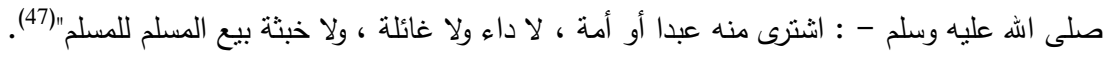

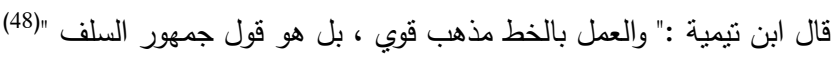

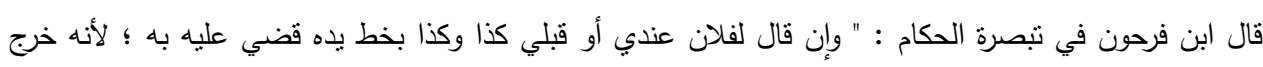

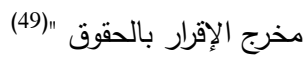

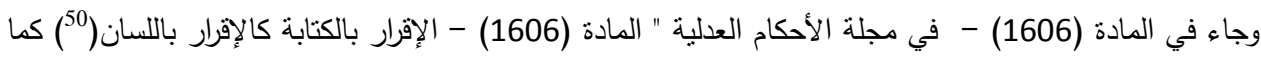

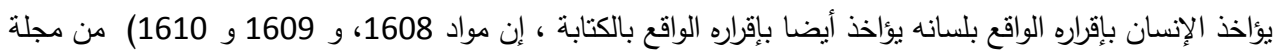

(43) الجوهري ، الصحاح تاج اللغة وصحاح العربية ، (ج 3/ص123).

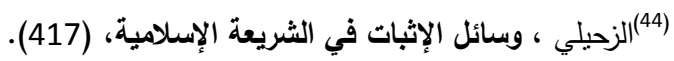

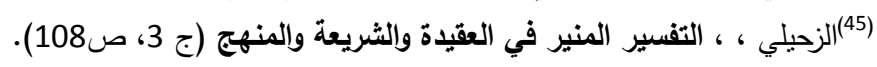

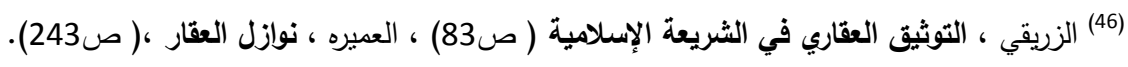

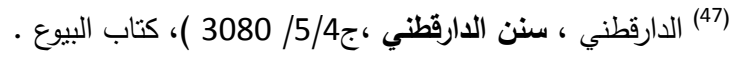

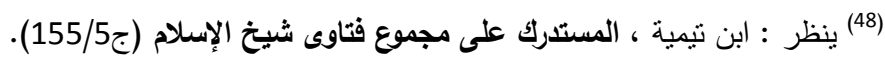

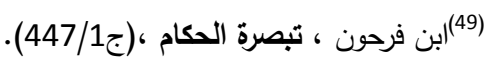

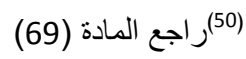




\section{Journal of Social Sciences (COES\&RJ-JSS), 8(1), pp.63-89}

الاحكام العدلية ، من قبيل الإقرار بالكتابة أما المادة الأتية فهي إقرار باللسان ، والإقرار بالكتابة معتبر سواء حصل

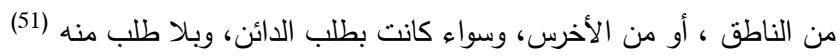
وهذا القول بلا شك هو الراجح والأدلة كثيرة ومنها ما جاءعن ابن عمر رضي الأنه الهن عنه أن رسول الله - صلى اله عليه

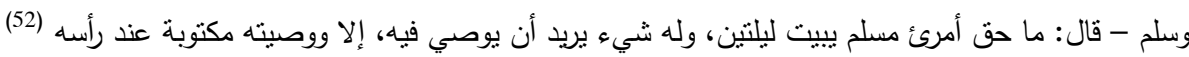
وقد اعترض على التوثيق بالكتابة إن الخطوط تتشابه وقد تتبدل وتزور وقد يكتب دون قصد البيع •

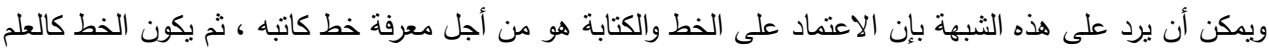
بنسبة قائلة إليه.

وكذلك مع النطور في العلوم الجنائيةفإن الخبير بالخطوط يسنطيع أن يعرف صاحب الكتابة.

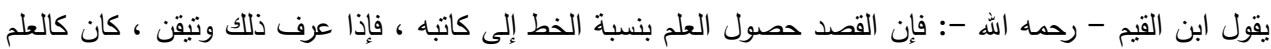
بنسبة اللفظ إليه ، فإن الخط دال على اللفظ ، واللفظ دال على القصد والإرادة، وغاية ما يقدر انتتباه الخطوط ، وذللك

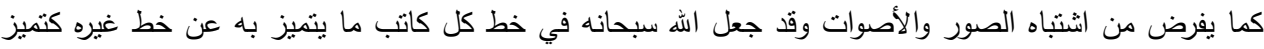

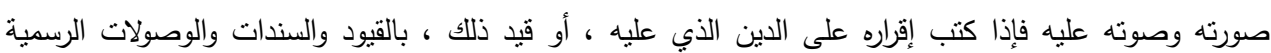

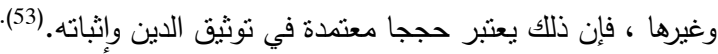

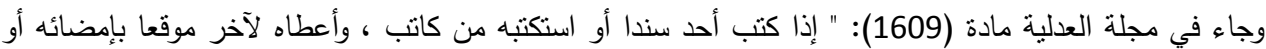
مختوما، فإذا كان مرسوما - أي حرر موافقا للرسم والعادة - فيكون إقرارا بالكتابة ، ويكون معتبرا ومرعيا كثقريره

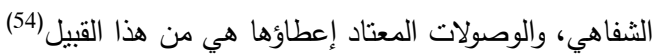

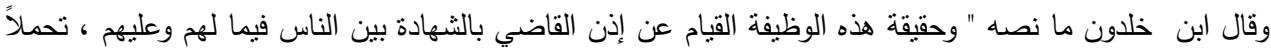

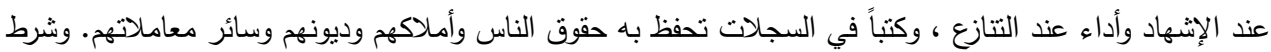
هذه الوظيفة الاتصاف بالعدالة الثرعية والبراءة من الجرح ، ثم القيام بكتب السجلات والعقود من جهة عبارتها وانتظام

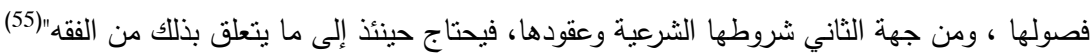

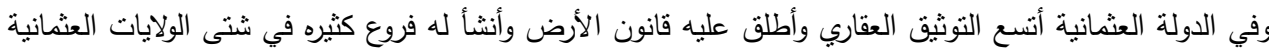

ومن هنا يتضح لي أن الكتابة تكون للتوثيق ، وهو التتبت ، والإحكام ، والتقوّى ، وقد يكونالتوثيق بالكتابة بالطريقة المعتادة ، والأسلوب المتعارف عليه ، حسب كل عصر، ويختلف حسب اختلاف الزمان والمكان ، والقصد منها حفظ الحقوق عن الضياع ، ولتثبت الحق عند التنازع لقطع الثقاق والخلاف في التفاصيل ، فالكتابة هي كل خط يوثق بها الحقوق بطريقة مشروعة، و مخصوصة يقوم بها أثخاص من أجل الرجوع إليها عند الحاجة .

(51) أفندي ، درر الككام في شرح مجلة الأحكام (ج159/4) التردئ.

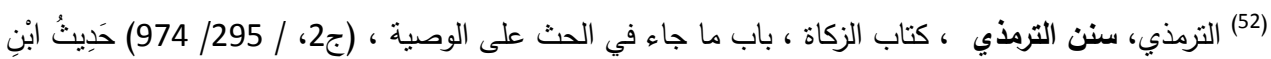

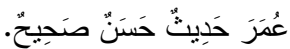

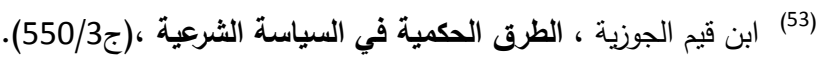

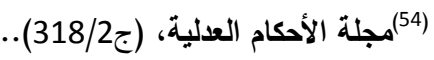

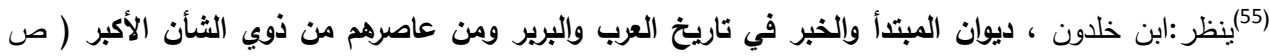

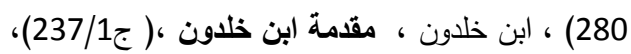

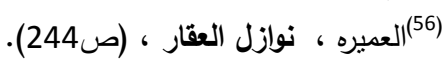




\section{Real estate documentation and its importance in Islamic jurisprudence and law}

الفرع الثاني : الثهادة : وهذه الثهادة تكون ممن شهد العقد أو الواقعة وقد أمر اله بإلاشهاد على الدين وغبرها من

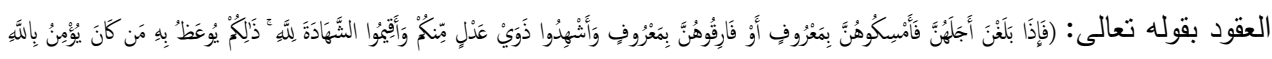

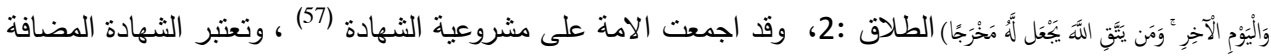

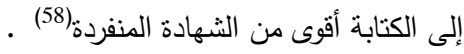

اولا : تعريف الثهادة لغة واصطلاحاً

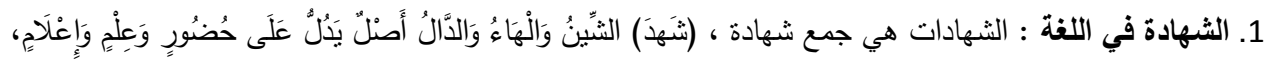
يقال : شهد يشهد شهادة ، وهي في اللغة لمعان عديدة كالعلم ، والحضور ، والرؤية، والإعلام، والإخبار ، والمعاينة. (59)

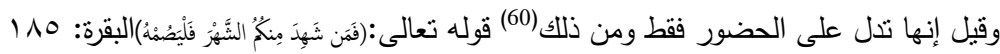
2.تعريف الثهادة اصطلاحاً:-

وعرفت شرعاً بإنها : إخبار بحقّ للغير على آخر عن يقين، وذللك المخبر يسمّى شاهداً (61).

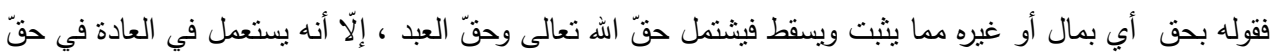

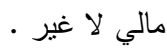
وقوله للغير أي حصل لغير المخبر من كلّ الوجوه كما هو المتبادر، فيخرج عنه الإنكار فإنّه إخبار لنفسه في يده،

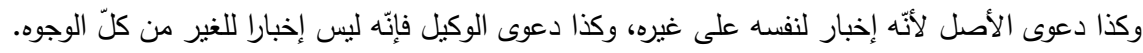

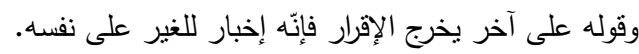

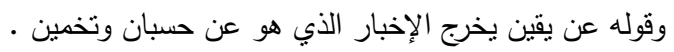

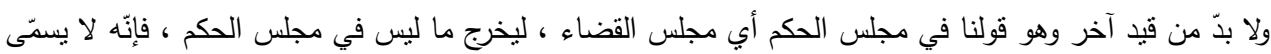
شهادة (62).

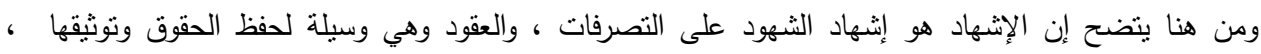

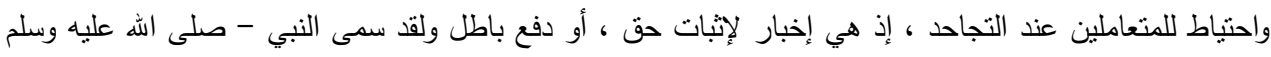

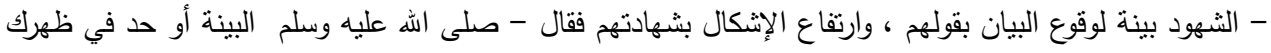

ثانياً: مشروعيتها وحكمها: والثهادة مشروعه تحملا وأداء وأنها مشروعة لتوثيق الدين والمعاملات وغيرها من سائر المعاملات (64 ) لقوله تعالى

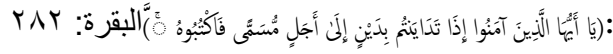

$$
\begin{aligned}
& \text { (57) الخن ، الفقه المنهجي على مذهب الإمام الثافعي ، (ج8/ص211). }
\end{aligned}
$$

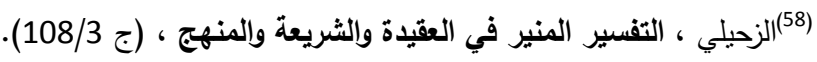

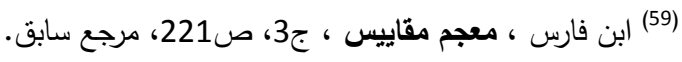

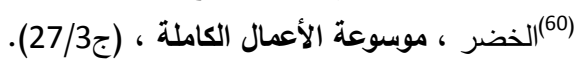

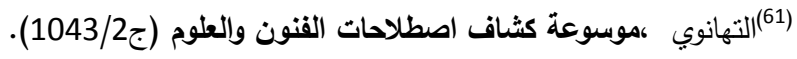

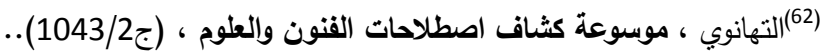

$$
\begin{aligned}
& \text { (63) ابن فرحون ، تبصرة الحكام في أصول الأقضية ومناهج الأحكام (ج1 /240) (240). }
\end{aligned}
$$

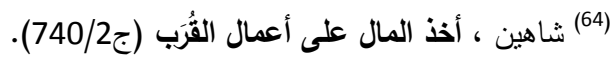


وهي مستحبة كما قال ابن العربي قال ابن العربي - رحمه الهه - : والظاهر الصحيح أن الإتشهاد ليس واجبًا ، وإنما

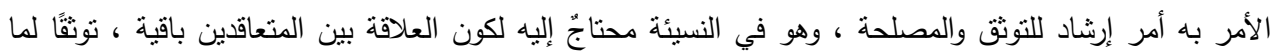

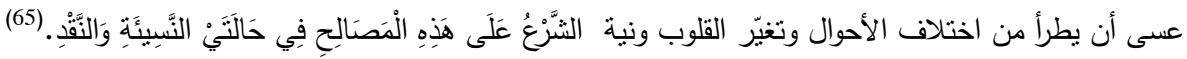

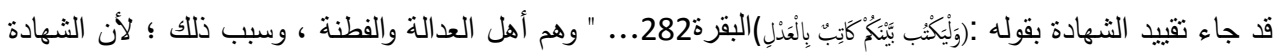
ولاية عظيمة تقتضي تتفيذ القول على الغير بدون رضاه.... ولهذا وجب أن يكونلصاحبها شمائل بنفرد بها وفضائل

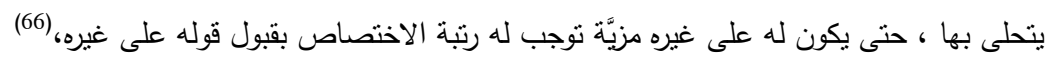

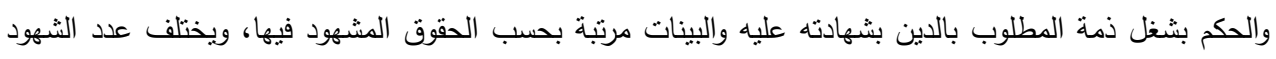
من حكم لآخر حسب الثهود فيه أيضا(67).

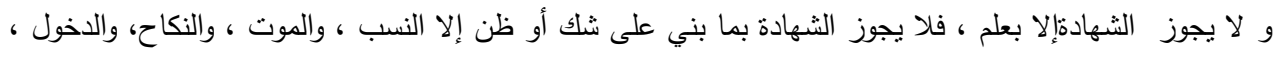

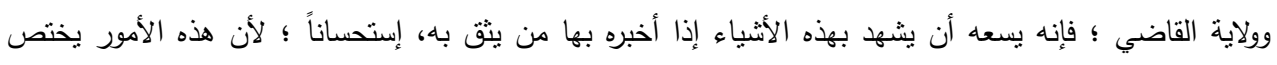

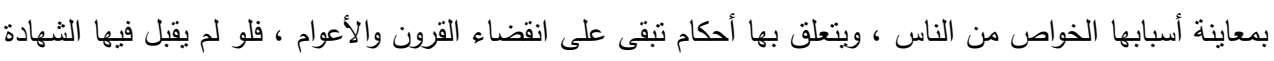
بالتسامع لأدى إلى الحرج وتعطيل الأحكام (68).

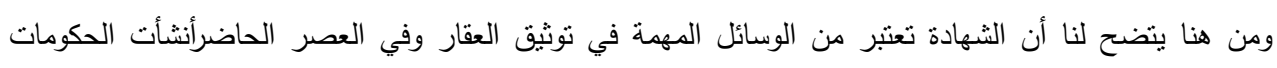

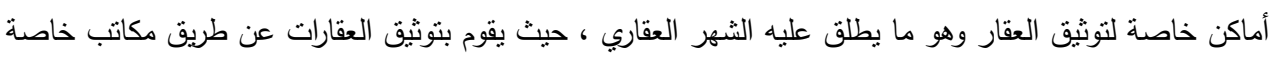

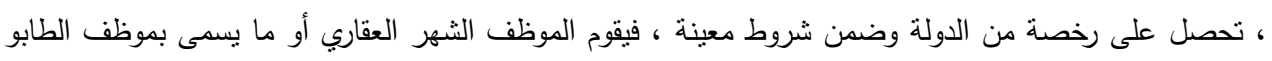

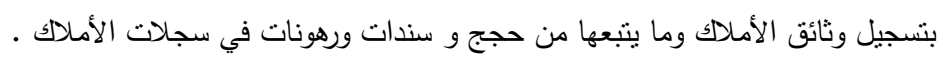

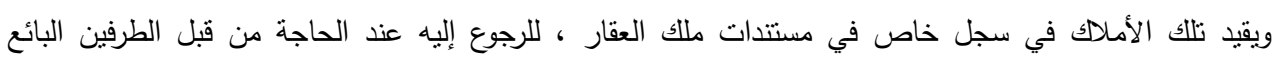

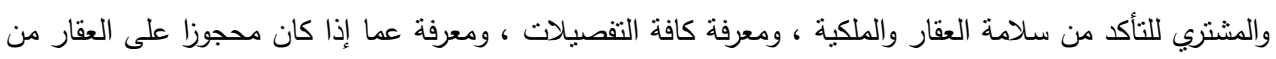

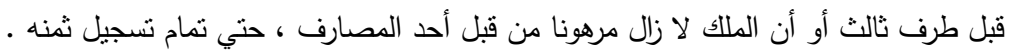

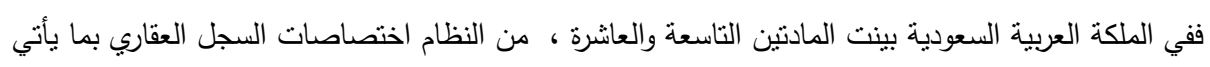

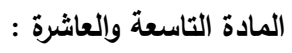

تتولى كل من : وزارة الثئون البلدية والقروية ، ووزارة العدل ، أعمال التسجيل العقاري والتوثيق وفقاً لما يأتي :

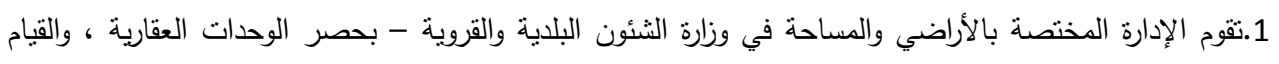

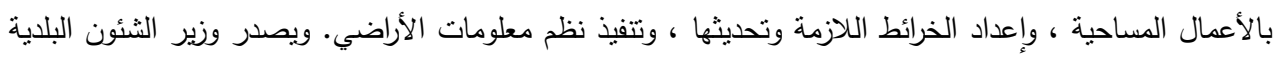

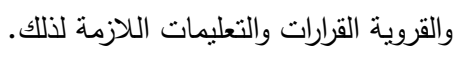

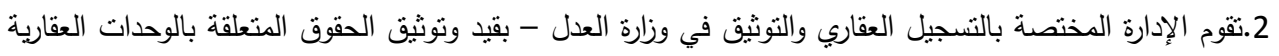

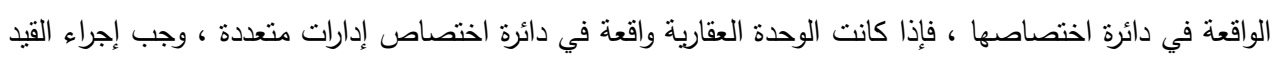

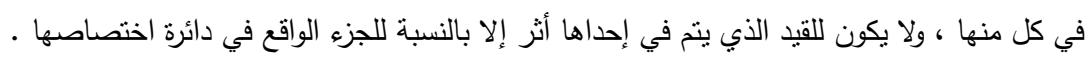

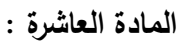

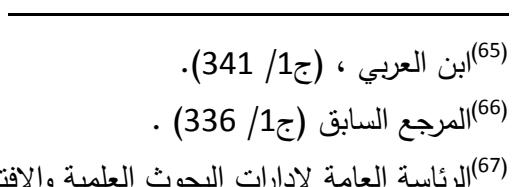
(67) الرئاسة العامة لإدارات البحوث العلمية والإفتاء والدعوة والإرشاد، مجلة البحوث الإسلامية (ج289/80).

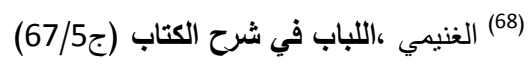




\section{Real estate documentation and its importance in Islamic jurisprudence and law}

تحفظ في إدارة التسجيل العقاري أصول الصكوك والأحكام التي ينم القيد بموجبها ، والسجلات والوثنائق الخاصة بالقيد

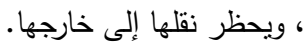
ولا يجوز لغير الجهات القضائية أو من تتدبه من أرباب الخبرة وهيئات النظر الاطلاععليها. ويستثى من ذلك الوثائق

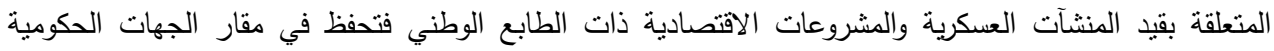

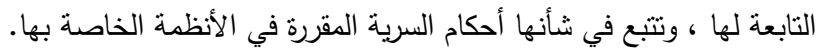

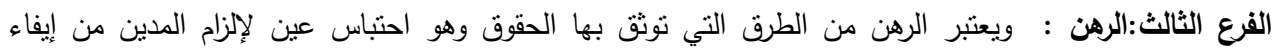

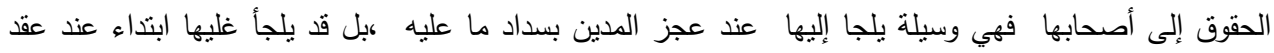

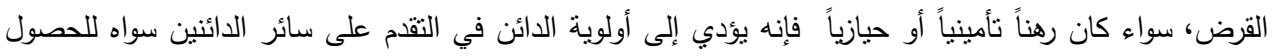

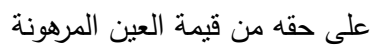
أولاً:تعريف الرهن لغة واصطلاهـا:

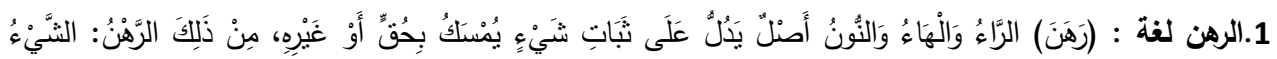

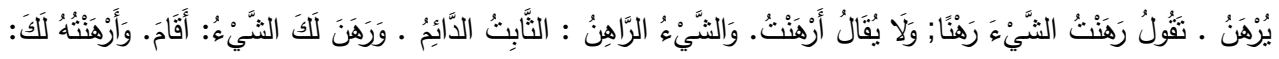

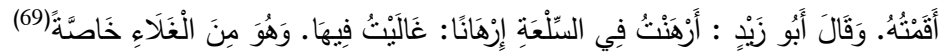

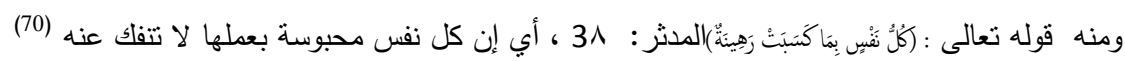

\section{2.الرهن في اصطلاح الفقهاء}

هناك عدة تعريفات للفقهاء للرهن ونظراً ؛ لأن التعريفات قد قتلت بحثنا فأنني سأورد تعريفات الفقهاء للارهن دون تطويل

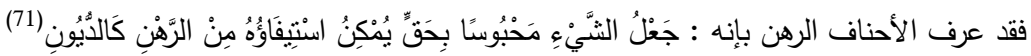

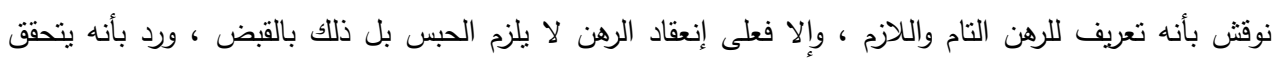

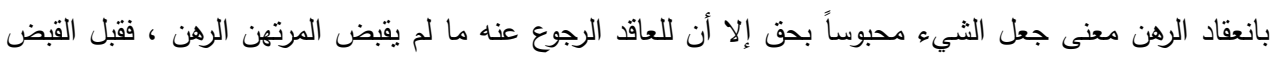

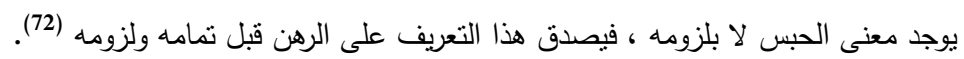

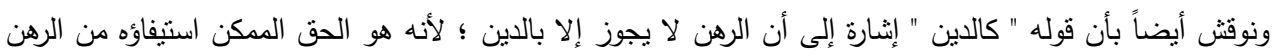
لعدم تعينه (73).

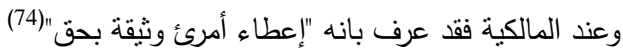

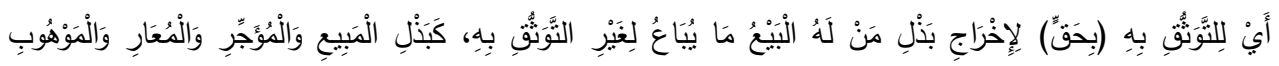

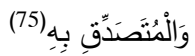
واعترض عليه بأنه غير مانع لدخول اليمين ليقضيه إلى أجل كذا ودفع الوثيقة المشهودة بالدين ونحو ذلك .

$$
\begin{aligned}
& \text { (69) ابن فارس ، معجم مقاييس اللفة (ج452/2)، ابن منظور ، لسان العرب (ج190/14). }
\end{aligned}
$$

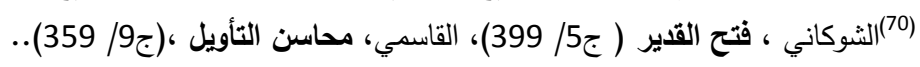

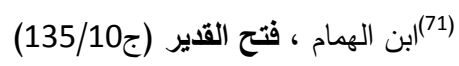

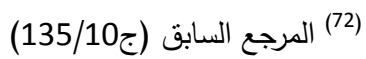

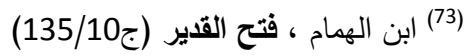

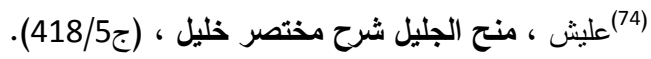

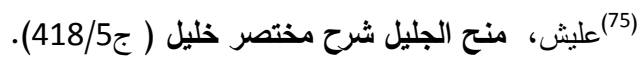


وأجيب عن ذلك بمنع قبول دخول شيء منها تحته لأن لفظة : ( إعطاء ) تقتضي حقيقة دفع شيء ، ولفظ : ( وثيقة

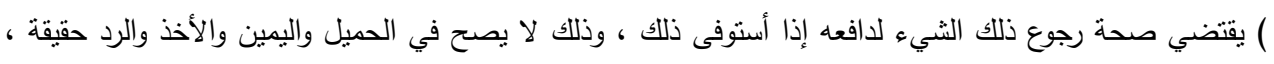

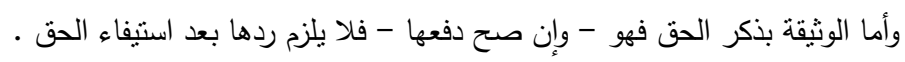

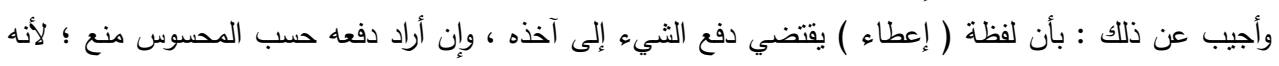

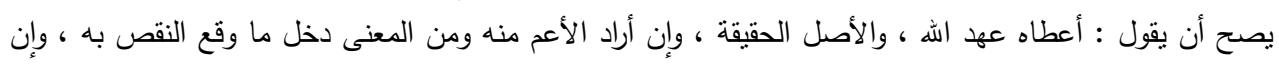
سلم كونه حسيًاً بطل بإخراج رهن الدين (76).

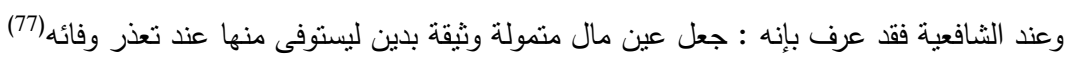

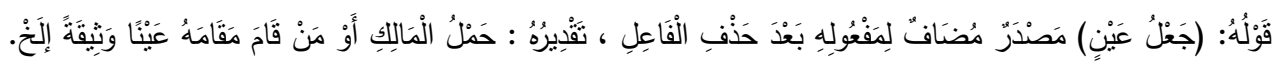

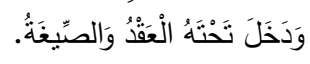

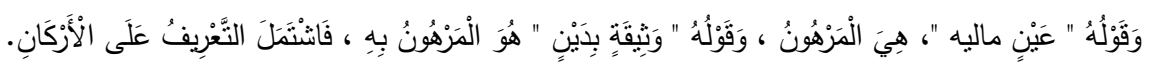

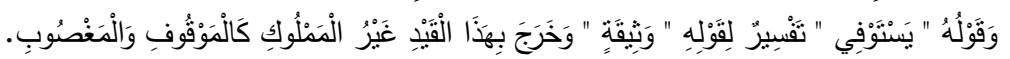

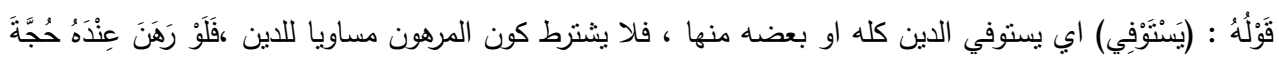

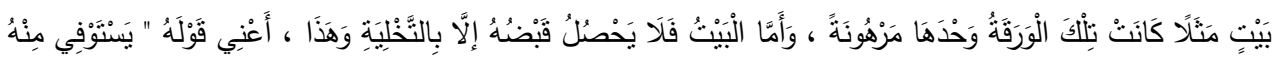

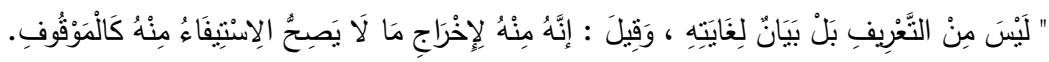

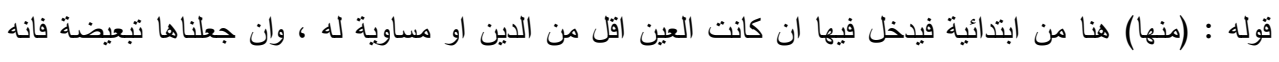

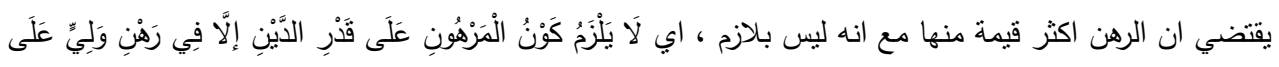

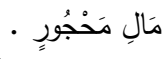

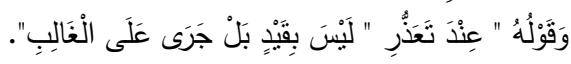

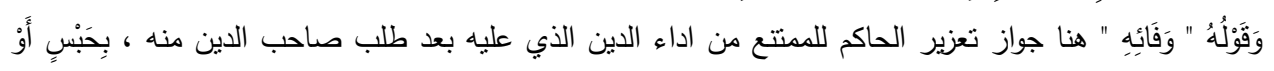

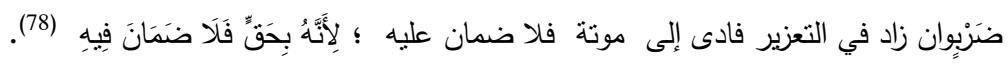

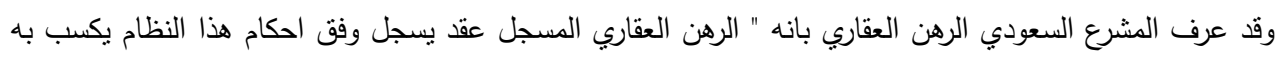

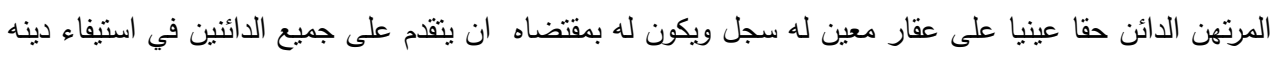
من ثمن ذلك العقار في اي يد يكون (79).

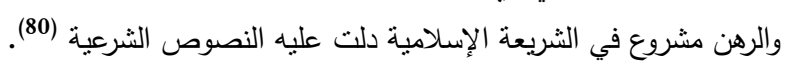

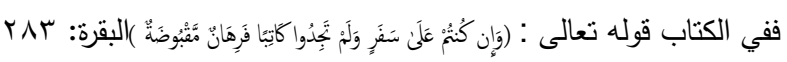

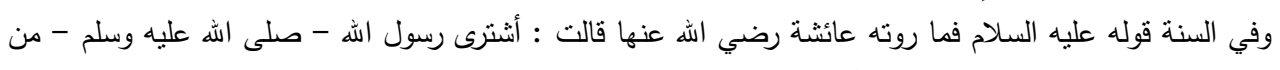
يهودي” طعامًا إلى أجل ورهنه درعه (81 ). .

(76)هيئة كبار العلماء بالمملكة العربية السعودية ، أبحاث هيئة كبار العلماء ( ج6 / (104).

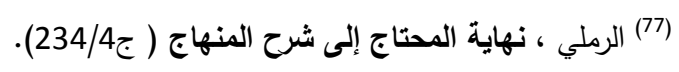

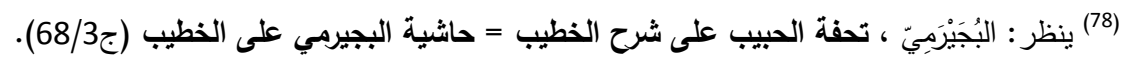

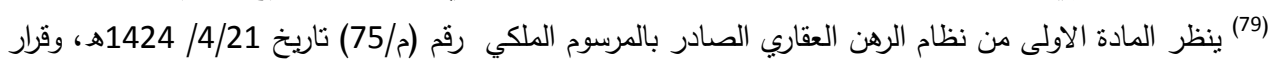

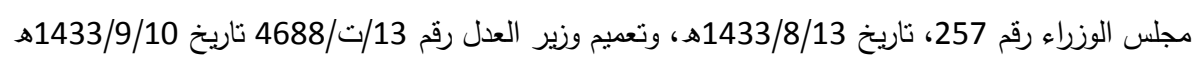

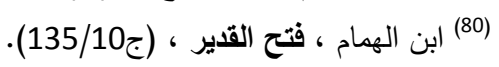
(81) البخاري ، صحيح البخاري ، كتاب الرهن ، باب من رهن درعه، (ج4 (135). (142/ 2509). 


\section{Real estate documentation and its importance in Islamic jurisprudence and law}

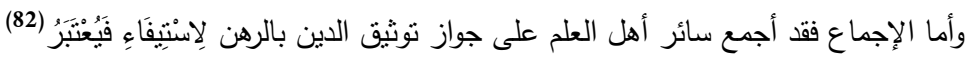

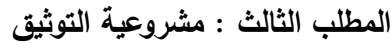
الفرع الأول : مشروعيته من القرآن الكريم

تعتبر آية الدين أطول آية في القرآن الكريم ، و هي أساس نظام التوثيق في الإسلام ، و فيما يأمر الحق سبحانه

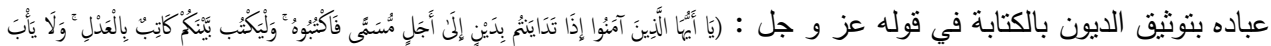

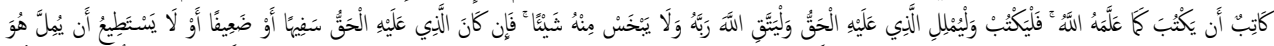

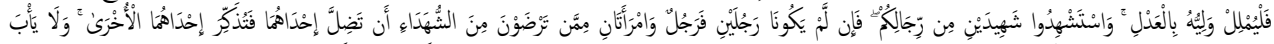

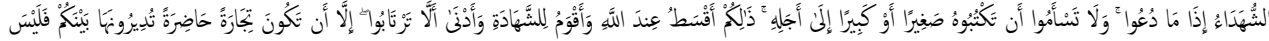

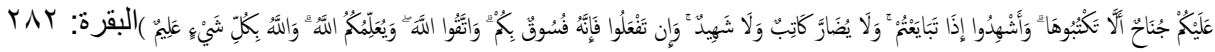

\section{الفرع الثاني: مشروعية هذه الأنواع من السنة}

وفيما يأني أمتلة مستقاة من سبرة النبي عليه السلام تدل على استعمال النبي عليه السلام لهذه الأنواع ، ما كتبه النبي الني

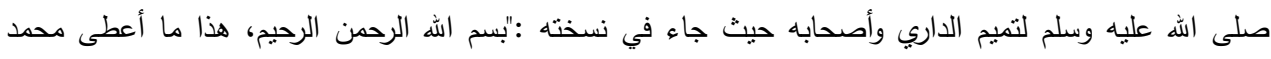

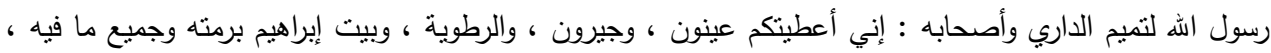

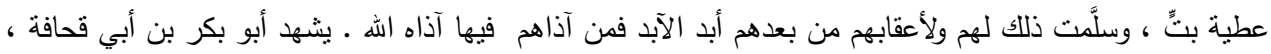

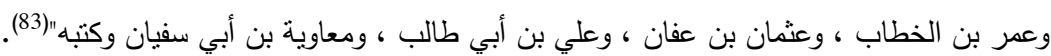

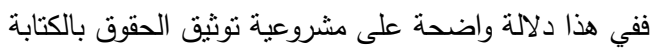

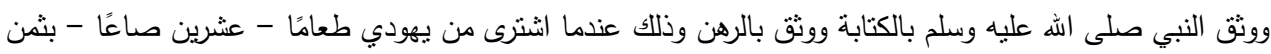

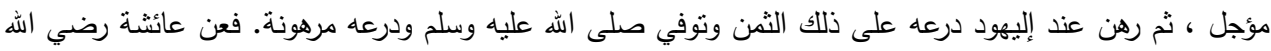

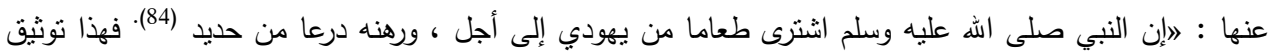
بالرهن كما كان التوثيق بالكتابة. وكذلك النبي صلى اله عليه وسلم بإلاشهاد فقدا روى النعمان بن بشير من قصة أمه مع أبيه إذ رغبت أمه إلى أبيه

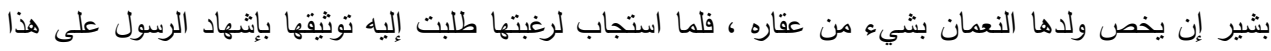

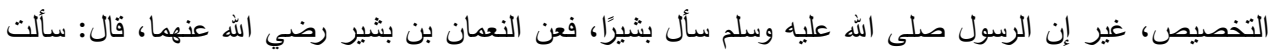

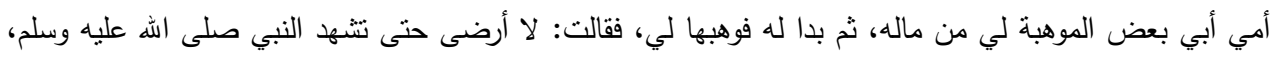

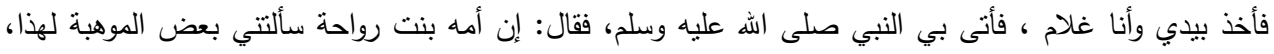

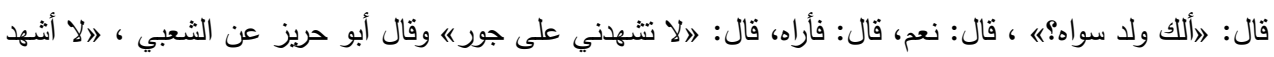
على جور (85). ورفض النبي عليه السلام الثهادة على هذا العطاء دليل على حجية الإثهاد في استيفاء الحقوق فمن هذه الأحاديث وفعل الصحابة يدل على بداية النوثيق العقاري في الإسلام وهو عبارة عن تصرفات واجتهادات

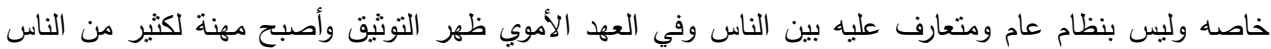

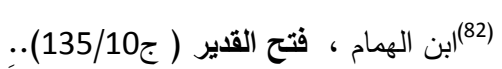

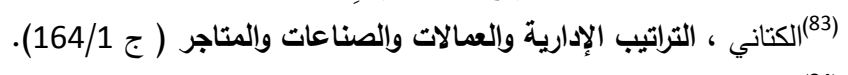

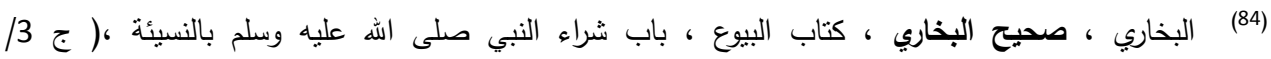

(85) البخاري ، صحيح البخاري ، كتاب الثهادات ، باب لا يشها على شهادة جور إذا أشهد ، (ج3/ 2650/171). 
ونثئ بعمل الثروط ثم تطور الأمر وأصبح أكثر شمولا ثم يقصد النوثيق على العقار بل يقوم الموثق باشمال توثيقه للشهادات و احكام ولغات (86).

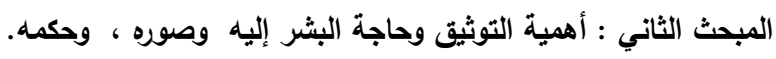

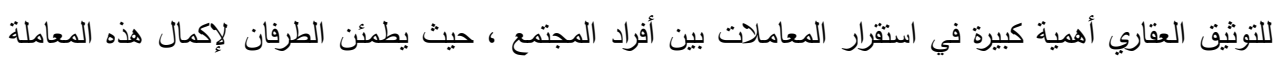

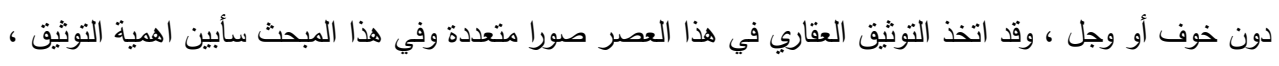

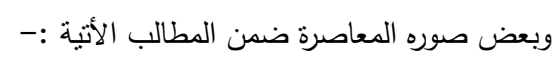
المطلب الاول : أهمية التوثيق العقاري

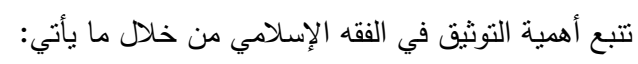

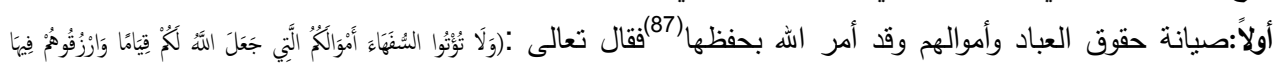

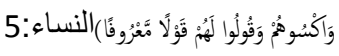

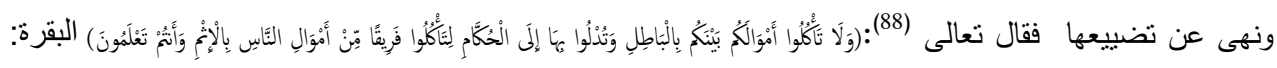
188

ثانياً : قطع المنازعات والخصومات التي تحدث بين الناس ، فيكون التوثيق مرجعاً وحكماً في فض الخصوم

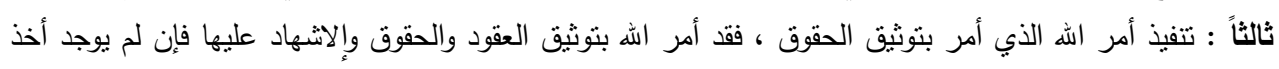

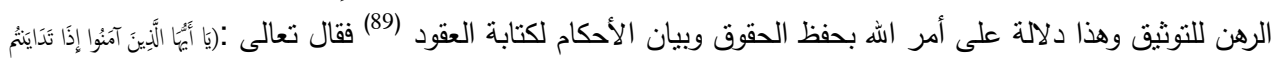

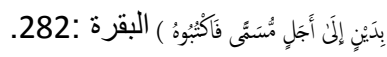

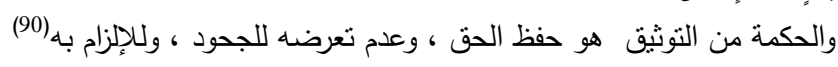

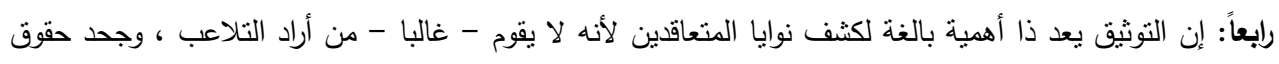

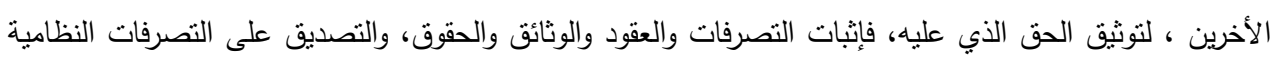

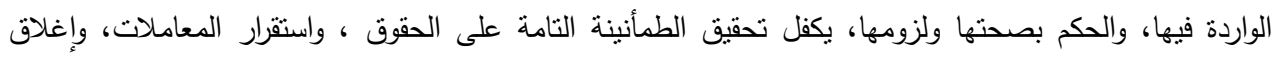
أبواب الحيل والتحايل ، والثر والمنازعات. خامساً : إن في النوثيق صيانة للأموال من أن تكون عرضة للضئ واتياع بإنكارها، وعدم التمكن من إثباتها.

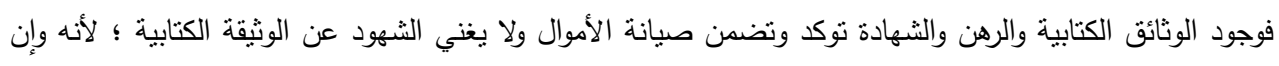

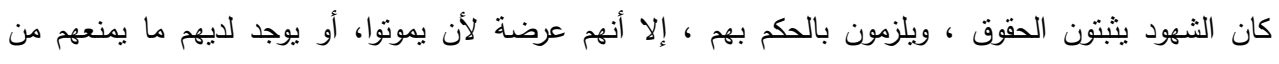

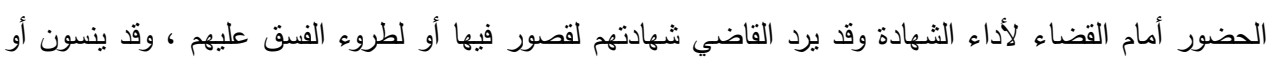

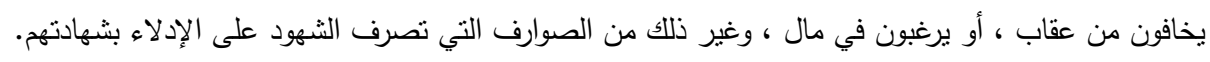

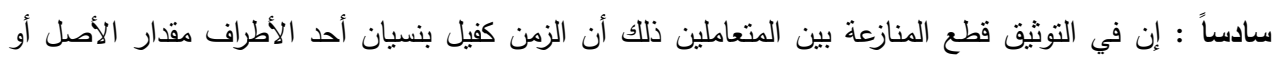

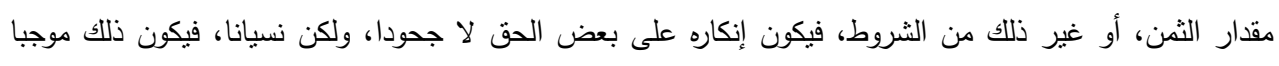

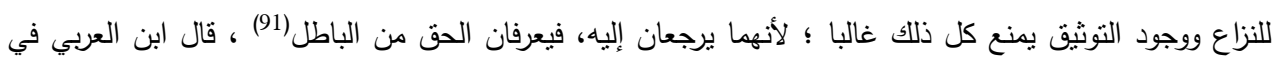

$$
\begin{aligned}
& \text { (86) العميري ، نوازل العقار، ( } 1 \text { (843،244). }
\end{aligned}
$$

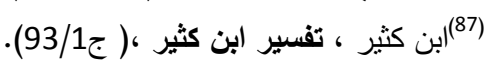

$$
\begin{aligned}
& \text { (88) ابن كثير ، تفسير ابن كثير ، (ج184/384). }
\end{aligned}
$$

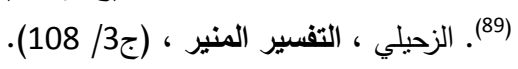

$$
\begin{aligned}
& \text { (90) (90) الزحيلي ، التفسير المنير ، (270/28). }
\end{aligned}
$$

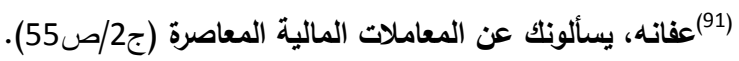




\section{Real estate documentation and its importance in Islamic jurisprudence and law}

حكمة مشروعية كتابة الدين قال : ليستذكر به عند أجله ، لما يتوقع من المدة التي بين المعاملة وبين حلول الأجل

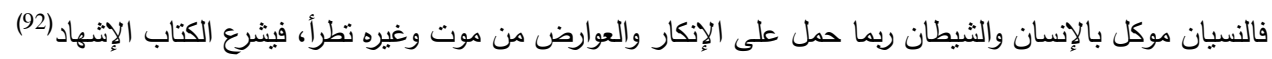

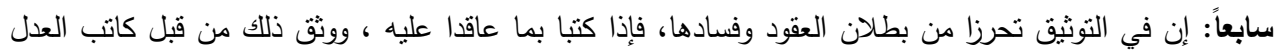

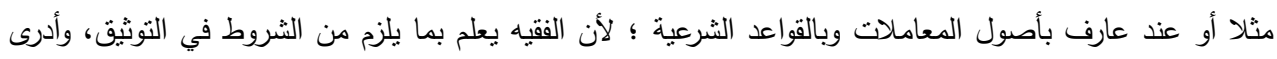

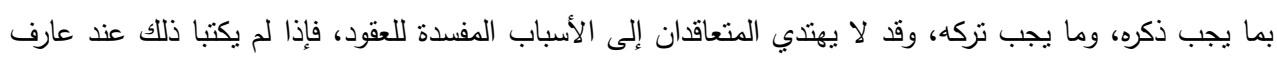

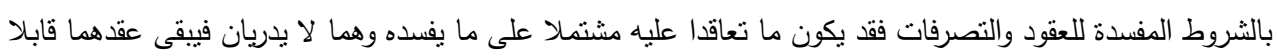

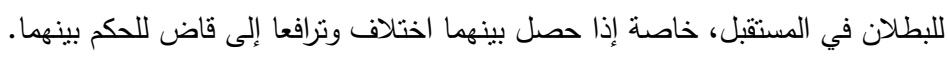

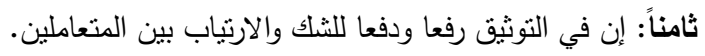

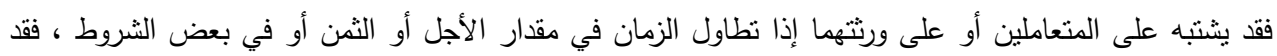

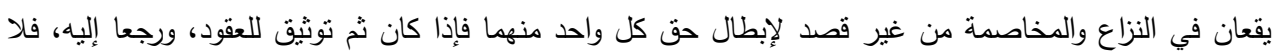
يبقى بعد ذلك شك ولا ارتياب.

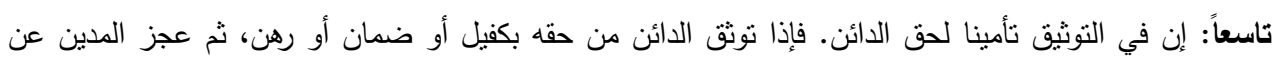

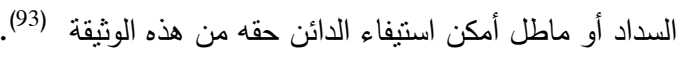

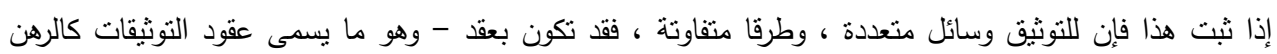

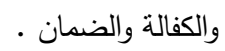
المطلب الثاني : صور التوثيق العقاري في وقتنا الحاضر وإجراءاتة النظامية : هناك ثلاث صور للتوثيث العقاري في العصر الحديث هي :

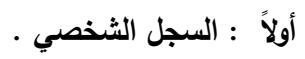
وقد عرف السجل الثخصي النظام الذي يعتمد على أسماء أصحاب الحقوق للقيد في السجلات المعدة لذلك ، فالقيد

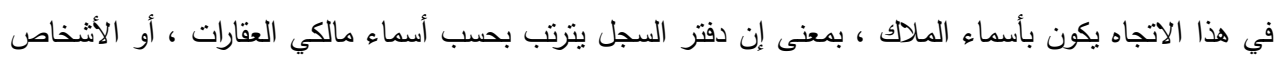

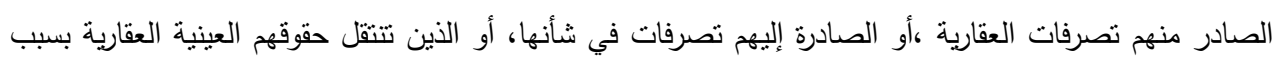

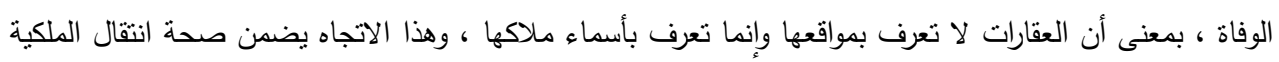

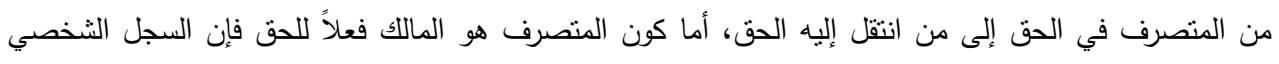

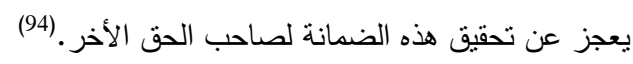

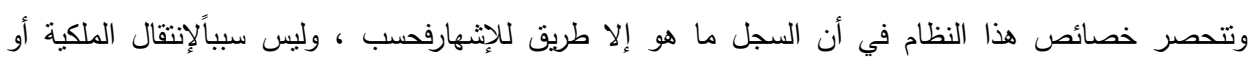
الحقوق العينية .

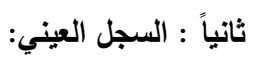

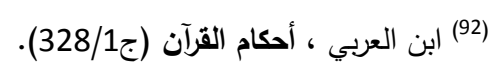

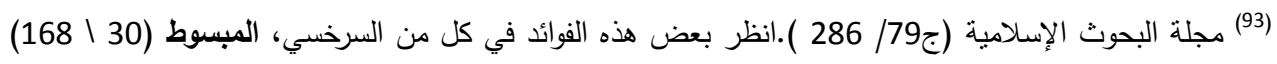

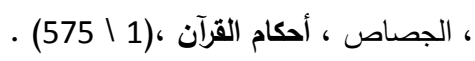
(94) ينظر ابو النجا ، السجل العيني في التشريع المصري ، العبري ، (ص27). 
ويقصد به النظام الذي يتخذ العقار أو الوحدة العقارية أساساً للقيد ، وهذا مبدا التخصيص ، ومعنى ذلك أنه تخصص

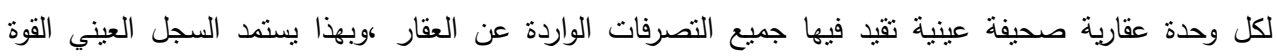
والثبوتية القاطعة عن الملكية (95)، وبهذا يمكن عند ارادة نقل ملك العقار الجزم بالمالك الفعلي للعقار . ثالثاً : وهو اتجاه بين هذين الإتجاهين

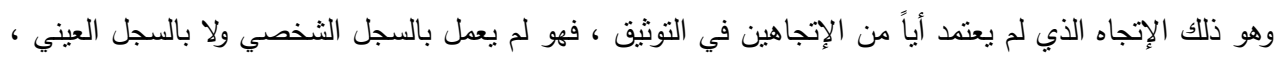

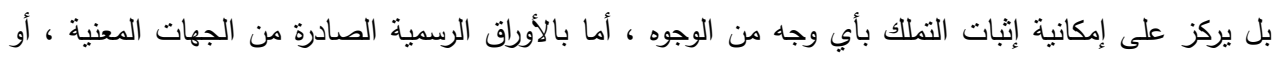

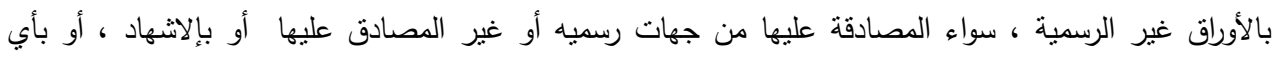

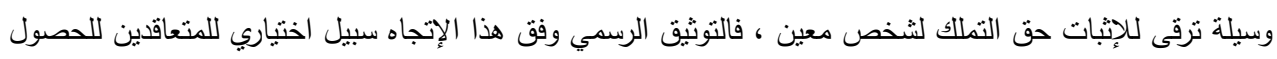

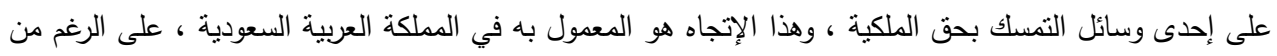
صدور نظام النسجيل العيني للعقار ، والذي صدر بالمرسوم الملكي رقم 12 هـهـ (96). وعلى هذا فإن التوثيق في المملكة ما زال يسبر وفق آلية قديمة نسير وفق المهج الثالث الثئ ، وتقسم هذه الآلية إلى قسمين :

أولاً: اثبات التملك الإبتدائي (97).

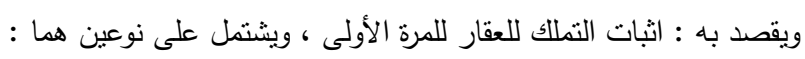
حجم الإستحكام. المنح بنوعيها الزراعية والسكينة.

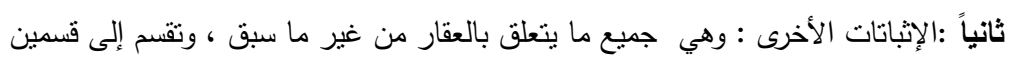

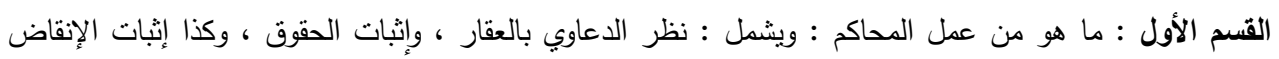
المقامة على العقار ، ودمج الصكوك (98). القسم الثاني :ماهو من عمل كتاب العدل ، منل المبايعات (الافراغات) ، وإثبات الرهون (99).

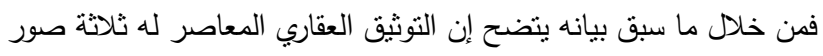

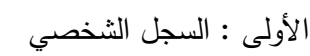

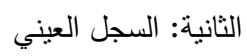
الثالثة : التوثيق المطلق (100). المطلب الثاني : أرآع الفقهاء في اعتبار التوثيق العقاري قبضاً وحكمه .

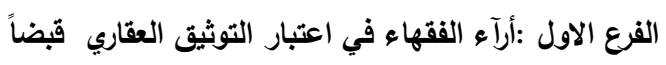

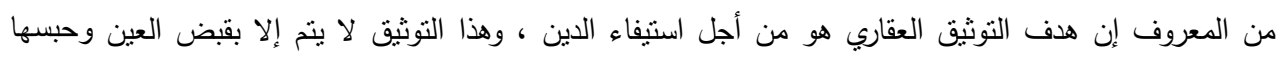

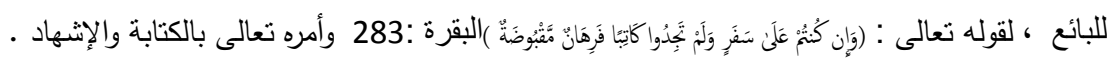

$$
\begin{aligned}
& \text { (95) المرجع السابق (ص44،42). } \\
& \text { (96) العميري ، نوازل العقار، (ص250). } \\
& \text { (97) الفراج ، تنظيم العقار وتوثيقه ، (ص) ، (5). }
\end{aligned}
$$




\section{Real estate documentation and its importance in Islamic jurisprudence and law}

وقد وقع خلاف فقهي بين الفقهاء المعاصرين حول اعتبار التوثيق العقاري قبضا أم لا إلى قولين :-

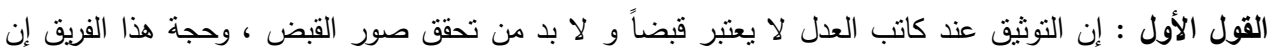

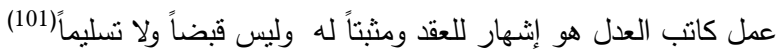
القول الثاني : يرى أن التوثيق العقاري يعتبر قبضاً ، سواء أكان على نظام النسجيل الثخصي أم التسجيل العيني

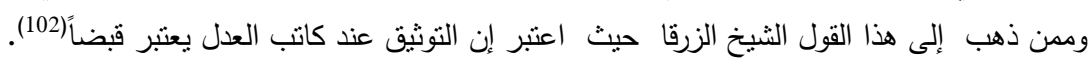

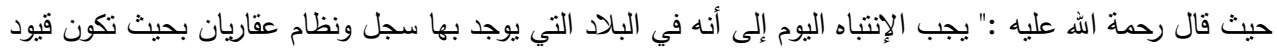

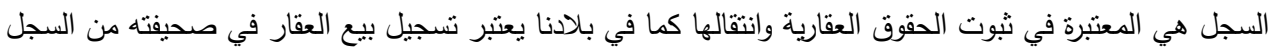

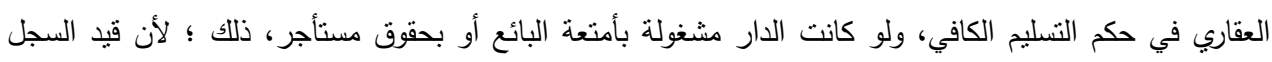

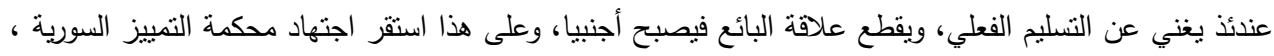

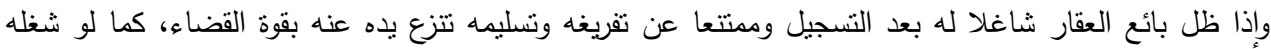
غصبا بلا حق بعد التسليم(103).

وذلك لأن نظام السجل العقاري أغنى عن قبض العقار المرهون بمجرد وضع إثارة الرهن عليه في صحيفته من

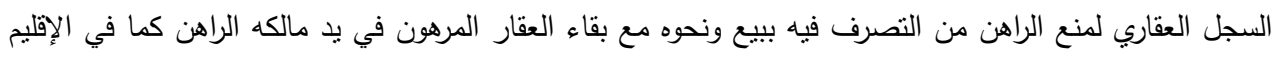

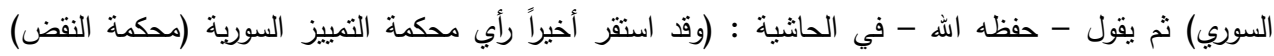
واجتهادها على أن تسجيل العقد العقاري في السجل العقاري يعتبر نسليماً قانونياً يقوم مقام التسليم الفعلي في نتائجه)

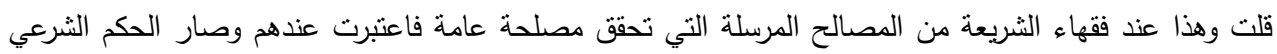
في هذه المسألة هو الحكم القانوني ذاته (104)

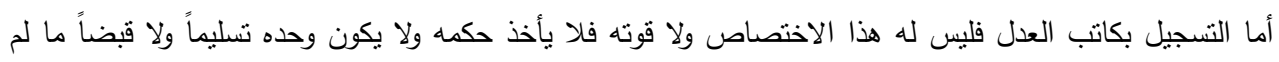

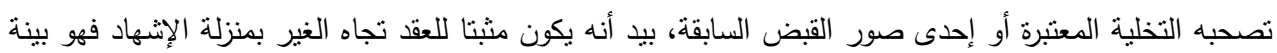

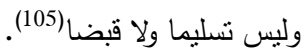
والذي ينضح إن التوثيق العقاري هو ما جمع بين الإتجاهين الكتابة والتوثيق لدى كاتب العدل وكذلك قبض العين لما يأني : 1.إن القبض لم يرد في تحديد صفته نص من الثارع فما تعارف الناس على إنه قبض يكون هو القبض المطلوب شرعاً (106) فقد اشتهر عند الفقهاء أن ما لبس له ضابط في اللغة و لا في الشرع يرجع فيه إلى العرف"(107)

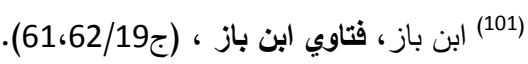

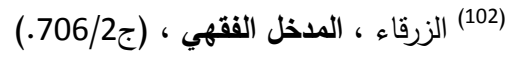

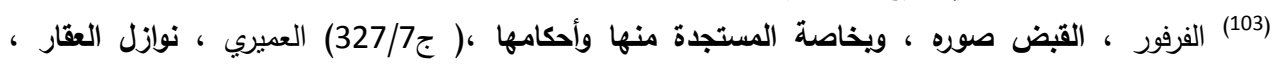

(104) (المرجعان السابقان (105)

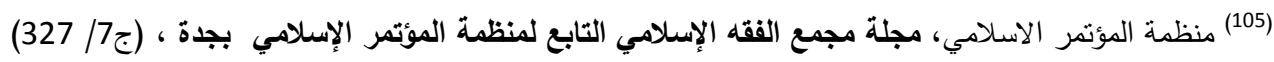

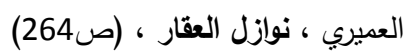
(106) المطيري ، رهـن العقـار رسميـً دراسة فقهية مقارنة بين الفقه والقانون الكويتي (م 4/ 2/ 2/ 45).

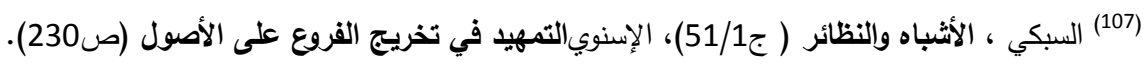




$$
\text { 2.قال البهوتي :" وكل ما لا حد له في الثرع برجع فيه إلى العرف كالحرز والقبض"(108). }
$$

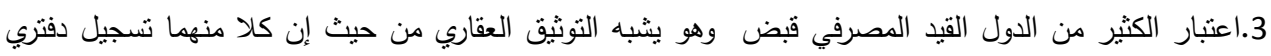
لإثبات حق (109).

والأصل في مصروفات كتابة السندات والحجج والصكوك التي نوثق العقود ورسوم التسجيل حسبما يشترطه العاقدان ، فإن لم يكن بينهما شرط يرجع إلى العرف (110).

فكل مصاريف التوثيق ترجع على صاحب المنفعة من التوثيق وهو المشتري للعقار وهذا معروف عرف عرفاً

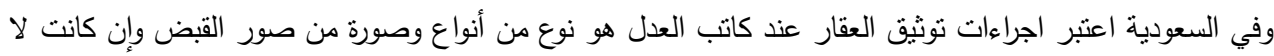
تقوى إلى نظام النسجيل الثخصي والعيني إلا إنها عرفاً تعد قبضاً (111). وقد جاء في قرار مجمع الفقه الإسلامي رقم (55 /4 /6) المنعقد في دورة مؤتمره السادس بجدة في المملكة العربية

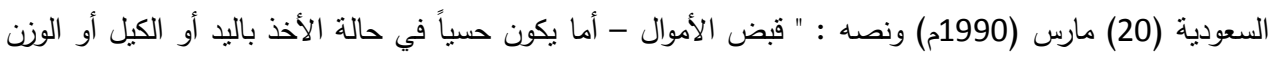

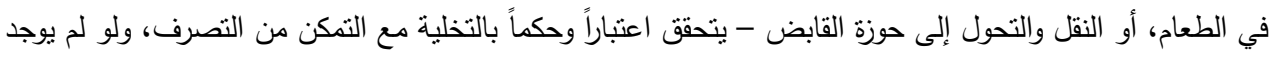

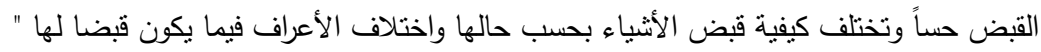

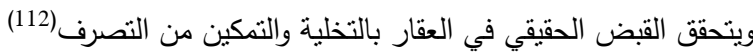
وقد اعتمد المجلس الثرعي المعيار الثرعي للقبض في اجتماعه (12) المنعقد في المدينة المنورة عام 2004م. (113) الفرع الثاني : حكم التوثيق العقاري ذهب جمهور أهل العلم من الحنفية(114) والمالكية(115)، والثنافعية(116)والحنابلة(117) إلى عدم وجوب التوثيق العقاري ،

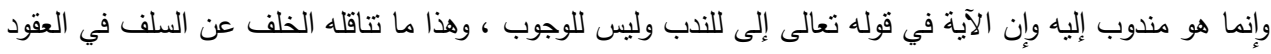

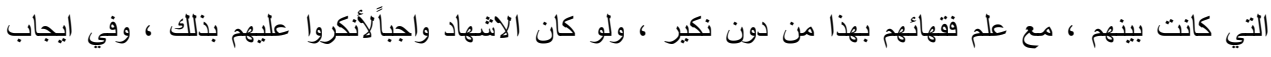

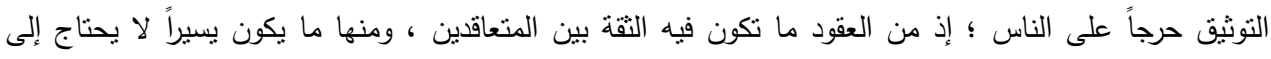

(108)(البهوتي ، كثاف القتاع عن متن الإقناع ، (ج3/263)؛ الرملي، نهاية المحتاج ،(ج38/5).

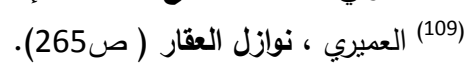

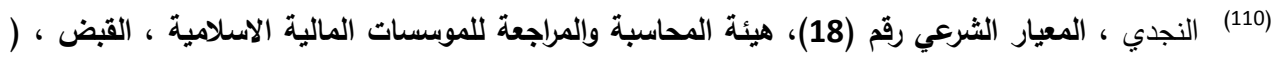

(112)(النجدي ، المعيار الثرعي رقم (18)، هيئة المحاسبة والمراجعة للموسسات المالية الاسلامية ، القبض ، (265).

(113) النجدي ، المعيار الثرعي رقم (182)، (ص263).

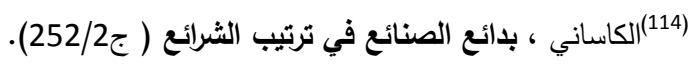

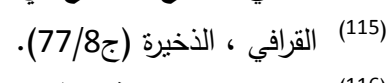

(116) العمراني ، البيان في مذهب الإمام الثافعي (7271/13).

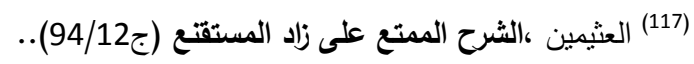
(118) الجصاص ، أحكام القرآن (ج585/1). 


$$
\begin{aligned}
& \text { والتوثيق في العصر الحديث بما يتضمن من تشريعات وأنظمة وقواعد من باب المصالح المرسلة التي يجوز أحداثها }
\end{aligned}
$$

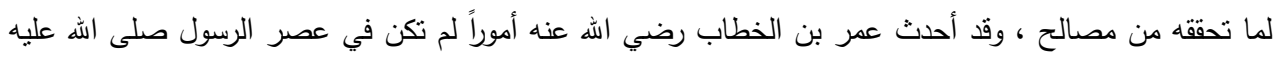

$$
\begin{aligned}
& \text { وسلم تحقيقِا للمصالح العامة كإحداثه الدواوين (119). } \\
& \text { والحمد له رب العالمين }
\end{aligned}
$$

$$
\text { الخاتمة وأهم التوصيات }
$$

الحمد لله رب العالمين وأفضل الصلاة وأنت التسليم على المبعوث رحمة للعالمين وبعد ، فبعد أن من الله علي بإكمال

$$
\text { هذه الدراسة فقد نوصلت إلى عدة نتائج منها لهابل }
$$

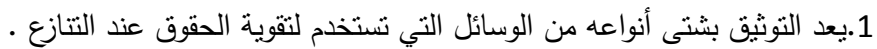

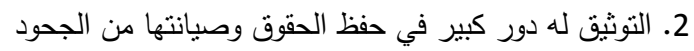

\section{References}

1. 1.Edwar Eid, Real Estate Systems, Selection and Editing - Land Registry, Dar Al-Thaqafa, Beirut, Lebanon, 1971,

2. $1382 \mathrm{AH})$, administrative structures, occupations, industries, shops and the scientific situation that was at the time of the establishment of the Islamic civilization in the scientific city of Medina, I 2, (Investigator: Abdullah Khalidi), Dar Al-Arqam - Beirut.

3. 2.Ibn al-Hasan al-Shafi'i, Abu Muhammad, Jamal al-Din (died: 772 AH), Preface in the graduation of branches on the origins, I, (Investigator: Mohamed Hassan Hito).

4. 3.The letter was submitted to the Higher Institute of Judiciary at Imam Muhammad Bin Saud Islamic University.

5. 4.Effendi, Ali Haidar Khawaja Amin (deceased: $1353 \mathrm{AH}$ ), Rulers in explaining the Journal of Judgments, I 1, (Arabization: Fahmi Husseini) Dar generation, 1991.,

6. 5.Qanwaji, Abu al-Tayeb Muhammad Siddiq Khan bin Hassan bin Ali Ibn Lutaf Allah Husseini al-Bukhari (died: 1307 AH), Abjad al-Uloom, 1, Dar Ibn Hazm, 2002.

7. 6.Amdi, Abulhassan Syed al-Din Ali bin Abi Ali bin Mohammed bin Salem al-Thaali alAmidi (died: $631 \mathrm{AH}$ ), rulings on the fundamentals of judgments, without a edition, (investigation: Abdel Razzaq Afifi), Islamic Bureau: Beirut

8. A committee composed of several scholars and jurists in the Ottoman Caliphate, AlAhdam al-Adliya Magazine, without a copy, (Investigator: Naguib Hawawini), Noor Mohammad, KaraghanTjart Books, Aram Bagh, Karachi

9. Abdullatif Ahmed Al-Sheikh, documentation of the scholars of the Maliki school, publications of the Cultural Center and the Friday Al Majid Center for Culture and Heritage in the United Arab Emirates, 2004.

10. Al Madina International University Curriculum, Sources of Literary Research and Sources, Al Madina International University, Al Madina International University

11. Aliish, Mohammed bin Ahmed bin Mohammed, Abu Abdullah al-Maliki (died: 1299 e), grant Galilee brief explanation Khalil, without printing, Dar al-Fikr: Beirut 1989 m.

$$
\text { (119) عميره ، نوازل العقار (ص254). }
$$


12. Al-Mubarak bin Ahmad bin Al-Mubarak bin Muhawb al-Lakhmi al-Erbil (d. $637 \mathrm{AH}$ ), the history of Erbil, without a copy. (Investigator: Sami bin Sayed Khammas al-Saqqar), Ministry of Culture and Information, Dar al-Rasheed Publishing, Iraq, 1980.

13. Amira, Ahmed bin Abdul Aziz, real estate forensic study of the most fundamental issues of contemporary real estate, Dar Al-Maiman - RIYADH, 1, $1432 \mathrm{AH}$

14. Ann Duzi, Reinhart Peter (d. $1300 \mathrm{AH}$ ), supplement of the Arabic dictionaries, i 1 (Mohammad Salim Al Nuaimi, Jamal Al Khayat), Ministry of Culture and Information, Republic of Iraq, 1979-2000.

15. Arabic, Judge Muhammad bin Abdullah Abu Bakr al-Maafari al-Ashbaily al-Maliki (died: 543 e), the provisions of the Koran, I 3, (see his origins and his speeches and commented on it: Mohamed Abdelkader Atta)

16. Baali, Abdul Hamid Mahmoud, Property and its Controls in Islam, Wahba Library, Cairo.

17. Baz, Fatawi Ibn Baz

18. Bjarmi, Sulaiman bin Mohammed bin Omar Al - Baghermi Al - Shafi'i (died: 1221 e), the masterpiece of the beloved on the explanation of the Khatib = the footnote Albajermi on Khatib, without printing, Dar Al - Fikr, 1995,.

19. Bukhari, Muhammad ibn Isma'il Abu Abdullah al-Bukhaari al-Ja'afi, the mosque of the right-hand man, the shortest of the things of the Messenger of Allah peace be upon him and his Sunnah and his days = Saheeh al-Bukhari, 1, (Investigator: Muhammad Zuhair bin Nasser al-Nasser) Mohamed Fouad Abdel Baqi), $1422 \mathrm{e}$

20. Buthi, Mansour bin Younis bin Salah al-Din Ibn Hassan bin Idris al-Hanbali (deceased: $1051 \mathrm{e})$, Scouts mask on the board of persuasion, the House of Scientific Books

21. Debian, Abu Omar Debian Bin Mohammed, Authentic and Contemporary Transactions, II, (Presented by Sheikh Sheikh Dr. Abdullah bin Abdul Mohsin Al Turki Sheikh Dr. Saleh bin Abdullah bin Humaid Sheikh Mohammed Bin Nasser Al Aboudi Sheikh Saleh Bin Abdul Aziz Al-Sheikh), King Fahad National Library, Riyadh - Saudi Arabia, 1432 AH.

22. Dharqutni, Abu al-Hasan Ali ibn Umar bin Ahmad bin Mahdi bin Masood bin Numan bin Dinar al-Baghdadi (died: 385 e), Sunan al-Darkutni, i, (achieved and edited and commented on it: Shuaib Arnaout, Hassan Abdel MoneimShalabi, Barhoum Foundation, Al-Resalah Foundation, Beirut, 2004

23. Farfur Mohammed Abdul Latif Saleh, arrested his image, especially the new ones and its provisions, member of the Islamic Figh Academy International Magazine Islamic Fiqh Academy of the Organization of the Islamic Conference in Jeddah, issued by the Organization of the Islamic Conference in Jeddah, the sixth issue

24. Farhoun, Ibrahim bin Ali bin Mohammed, Burhan al-Din al-Yamari (deceased: 799 e), the foresight of the rulers in the assets of the districts and curriculum curricula, I 1, library AlAzhar colleges,

25. Faris, Ahmad ibn Zakaria al-Qazwini al-Razi, Abu al-Hussein (d. 395 AH), Dictionary of Language Standards, no edition, (Investigator: Abdel Salam Mohammed Haroun), Dar alFikr, 1979.

26. Francis Rogers, The Story of Writing and Printing from the Engraved Rock to the Printed Page, The Anglo-Egyptian Library Cairo, 1969, p. 231, see also: Shafiq Shehata, on Documentation in Ancient Iraq's Civilizations, Dar al-Kutb for Printing and Publishing, Mosul, Iraq

27. General Presidency of the Departments of Scientific Research, Ifta, Da'wah and Guidance, Journal of Islamic Research - Journal issued by the General Presidency of the Departments of Scientific Research, Ifta, Da'wah and Guidance 
28. Ghani, Abdul Ghani bin Taleb bin Hamada bin Ibrahim al-Damashqi Field Hanafi (died: $1298 \mathrm{AH}$ ), the pulp in explaining the book, without printing, (achieved, and separated, and tuned, and commented Hawashih: Mohamed Mohieddin Abdel Hamid), scientific library, Beirut - Lebanon.

29. Haji Khalifa, Mustapha Ben Abdallah, writer of the Chalabi of Constantinople famous as Haji Khalifa or (deceased: 1067 e), revealed the suspicions of the books and the arts, the library Muthanna - Baghdad (and photographed several Lebanese roles, the same numbering pages, Modern Sciences, Scientific Research House, 1941, c.

30. Hammam, Kamal al-Din Muhammad ibn Abd al-Wahid al-Siwasi (died: 861 AH), Fatah alQadeer, without a edition, Dar al-Fikr without a date.

31. Jabal, the derivative dictionary of the Holy Quran

32. Jassas, Ahmed bin Ali Abu Bakr al-Razi al-Jassas al-Hanafi (deceased: $370 \mathrm{AH}$ ), the provisions of the Koran, i 1, (Investigator: Abdel Salam Mohamed Ali Shaheen)

33. Journal of Islamic Figh Academy of the Organization of the Islamic Conference in Jeddah Author: Issued by the Organization of the Islamic Conference in Jeddah.

34. Journal of Islamic Research Browse Volume No.> Issue No. 79 - Issue: From Rajab to Shawwal $1427 \mathrm{AH}>$ Research> procrastination of its manifestations, damages, types and causes in Islamic jurisprudence> The first topic and the obligation to discharge the rights of rights $>$ Third requirement The importance of the documentation of rights and means.

35. Kartabi, Abu Abdullah bin Mohammed bin Ahmed bin Abi Bakr bin Farah Al-Ansari Khazraji Shams al-Din (died: 671 e) the whole provisions of the Koran, interpretation of the Koran, I 2, (investigation: Ahmed Bardouni and Ibrahim Atfish), the Egyptian Book House - Cairo, 1964, , P. 377

36. Kasani, Alaeddin, Abu Bakr bin Masoud bin Ahmed Hanafi (d. 587 AH), Bada'id al-Sanayeh in the order of the laws, 2, Dar al-Kuttab al-Ulami, 1986

37. Khader, Muhammad al-Khader Hussain Imam Muhammad al-Khader Hussain (d. 1377 $\mathrm{AH}$ ), Encyclopedia of the Complete Works, i 1, collected and controlled by lawyer Ali alRedha al-Husseini, Dar al-Nawader, Syria, 2010.

38. Khaldoun, Introduction by Ibn Khaldun, Al-Warraq Website, http://www.alwarraq.com

39. Light, The Pharaonic Property and its Determination in Islam, 1, Cairo, 1964

40. Mansoor, Muhammad ibn Makram bin Ali, Abu al-Fadl, Jamal al-Din al-Ansari al-Ruwaifi (d.

41. Mosleh, Abdullah, Private Equity in Islamic Law, International Federation of Islamic Banks

42. Mouniaoui, Mahmoud Ben Mohamed Ben Mustapha Ben Abdellatif, Preface - A Brief Explanation of the Origins of Fundamentals, I 1, The Comprehensive Library: Egypt, 2011

43. Muhammad Mustafa Al-Zuhaili, Proofs in Islamic Law, Dar Al-Bayan Library, Damascus, I

44. Muhammad, Nasser, Endings in the Shari'a Courts of Saudi Arabia,

45. Mu'nis, RaedNasri, the following allowances, Ph.D.

46. Muqaddam, Zaid Hamza, Civil Transaction Documentation by "Comparative Study" Journal of Sharia and Law No. (26) Shawwal 1436 AH, August, 2015 AD

47. Mutairi, DaijBathi, Mortgage Property Officially A Comparative Jurisprudence Study Between Jurisprudence and Kuwaiti Law, Journal of Sharjah University of Shari'a and Humanities, 2007, Volume 4.

48. Nafrawi, Ahmed bin Ghanem (or Ghonaim) bin Salem bin Muhanna, Shihab al-Din alAzhari al-Maliki (deceased: 1126 e), fruits Aldwani on the letter of Ibn Abi Zayd alQairawani, no edition, Dar al-Fikr, 
49. Naja, Musa bin Ahmed bin Musa bin Salim bin Isa bin Salem Al-Hijawi Al-Maqdisi, and then Salhi, Sharaf al-Din, (deceased: 968 e), persuasion in the jurisprudence of Imam Ahmad bin Hanbal, without printing, (Investigator: Abdul Latif Mohammed Musa alSabki) Knowledge Beirut - Lebanon

50. NajdiRa'if Abd al-Rahman, Shari'a Standard No. (18), Accounting and Auditing Organization for Islamic Financial Institutions, Arrest

51. Nayef bin Juman al-Jaridan, (2012), Documentation Contracts, http://fiqh.islammessage.com

52. Nkari, Judge Abdul-Nabi Ibn Abdul-Rasul Al-Ahmad (deceased: S 12 e), The Constitution of the Scholars (the University of Science in the conventions of the arts)

53. Qana, Eltaher, (2006-2007), Role of Distribution of Property in the Islamic Economy, Master Thesis, University of Haj Lakhdar-Batna, Algeria

54. Qasimi, the virtues of interpretation

55. Rada'a, Muhammad Ibn Qasim Al-Rasa, Explanation of Ibn Arafa's Limits, No edition, Dar Al-Gharb Al-Islami: Beirut, 1993

56. Ramli, Shams al-Din Muhammad ibn Abi al-Abbas Ahmad ibn Hamza Shahab al-Din alRamli (died: 1004 e), the end of the needy to explain the curriculum, my last, Dar al-Fikr: Beirut, 1984.

57. Razi, Muhammad ibn Abi Bakr bin Abdul Qader Hanafi al-Razi (666 AH), Mokhtar alSahah, I 5, (investigation, Yusuf Sheikh Mohammed), Modern Library - Model House: Beirut, 1999

58. Sabki, Taj al-Din Abdul Wahab ibn Taqi al-Din (died: 771 e), Ashaba and isotopes, I 1, the House of Scientific Books, 1991.

59. Sawi, Abu al-Abbas Ahmad ibn Muhammad al-Khaluti (died: $1241 \mathrm{e}$ ), in the language of salik to the closest tract known as the footnote to the small annotation (small explanation is the explanation of Sheikh al-Dardair for his book called the closest path to the doctrine of Imam Malik), without printing,

60. Shaheen, Adel bin Shaheen bin Mohammed, Taking the money on the works of proximity, I 1, House treasures of Seville for publication and distribution, 2004.

61. Shukani, Muhammad bin Ali bin Mohammed bin Abdullah Al-Yamani (deceased: 1250 AH), Fath al-Qadeer, I 1, Dar Ibn Katheer, Dar al-Kalim al-Tayeb - Damascus, Beirut, 1414

62. Siwasi, Kamal al-Din Muhammad ibn Abd al-Wahid (681 e), explain Fatih al-Qadeer, Dar al-Fikr Place of publication: Beirut.

63. Sufi Hassan, History of Legal and Social Systems, Dar al-Nahda al-Arabiya, Cairo, Egypt, 1972.

64. Suwayti, Abdul Rahman bin Abi Bakr, Jalal al-Din al-Suyuti (deceased: 911 e), Ashaba and isotopes, Dar al-Kuttab al-Ulami, I 1, 1990

65. Tahani, Muhammad bin Ali Ibn al-Qadi Muhammad Hamed bin Mohammed Saber AlFarouqi Hanafi (deceased: $1158 \mathrm{AH}$ ), Encyclopedia of the Scouts of Arts and Sciences, 1, (Presentation, supervision and review Rafiq Al-Ajam Inquiry, Ali Dahrouj Transferring the Persian text to Arabic, George Zinani), Lebanon Publishers Library - Beirut, 1996. .

66. Tameya, Taqi al-Din Abu al-Abbas Ahmad ibn Abd al-Halim al-Harani (died: 728 AH), Almstadrak on the total fatwas of Shaykh al-Islam, I 1, (collection and rank and printing at his expense: Muhammad bin Abdul Rahman bin Qasim (deceased: 1421 e)), 1418 e.

67. The Council of Senior Scholars in the Kingdom of Saudi Arabia 


\section{Real estate documentation and its importance in Islamic jurisprudence and law}

68. The values of the nutmeg, Abu Abdullah Muhammad ibn Abi Bakr ibn Ayyub (691 - 751), the methods of governance in the politics of legitimacy, I 1, (Investigator: Nayef bin Ahmed Al-Hamad)

69. Tirmidhi, Muhammad bin Isa bin Surah Ibn Musa al-Dahhak, Abu Issa (deceased: 279 e), the Great Mosque - Sunan al-Tirmidhi, no edition, (Investigator: Bashar AwwadMa'arouf), Dar al-Gharb al-Islami, Beirut, 1998.

70. 'Uthaymeen Muhammad bin Saleh bin Muhammad (died: 1421 AH), al-Sharh al-Mumti' Ali Zad al-Mustaqna ', 1, Dar al-Jawzi, 1422-1428

71. Yahya bin Abi Al-Khair bin Salem Al-Omrani Al-Shafi'i (died: $558 \mathrm{AH}$ ), the statement in the doctrine of Imam Shafi'i, I 1, (Investigator: Qasem Mohammed Al-Nouri), Dar Al-Manaj Jeddah, 2000

72. Yousef Al - Qadaj (1445 AH), Organization of Real Estate and Tunica, Research presented in the real estate and legal systems of the Ministry of Justice in Saudi Arabia.

73. Zahra, Muhammad, Property and Contract Theory in Islamic Law, Dar Al-Fikr Al-Arabi, Cairo

74. Zawriqi, Juma Mahmoud, Real Estate Documentation in Islamic Law, I 1, Publication of the General Establishment for Publishing, Distribution and Advertising Tripoli, Libyan Arab Jamahiriya, 1985.

75. Zmakhshari, Abu al-Qasim Mahmud bin Amr bin Ahmed, Jarallah (deceased: 538 e), the search for the facts of the mystery of download, i 3, Dar al-Kitab al-Arabi - Beirut, $1407 \mathrm{e}$

76. Zuhaili, Wahba bin Mustafa, interpretation of enlightenment in the doctrine and Shari'ah and curriculum, I 2, Contemporary Thought House - Damascus 1418. 